
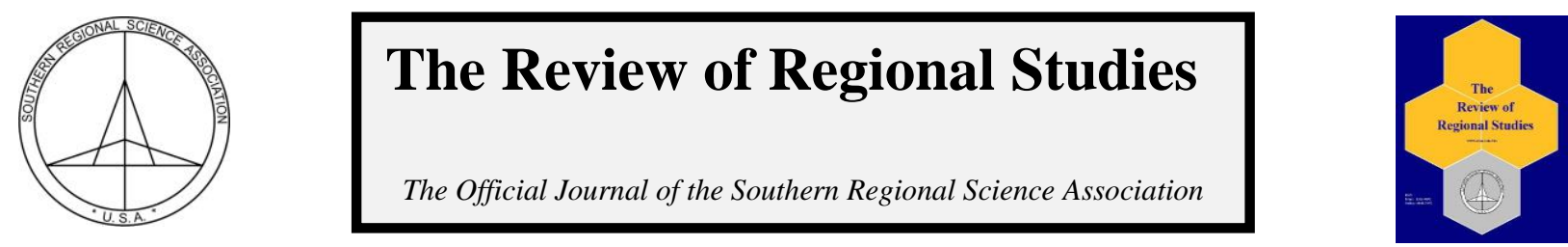

\title{
Improved Spatially Disaggregated Livestock Measures for Uganda*
}

\author{
Carlo Azzarri ${ }^{\mathrm{a}}$, Elizabeth Cross $^{\mathrm{b}}$ \\ ${ }^{a}$ International Food Policy Research Insitutte (IFPRI), Washington, DC, USA \\ ${ }^{b}$ United States Bureau of Labor Statistics (BLS), Washington, DC, USA
}

\begin{abstract}
The objective of our study is twofold: on one side, to complement earlier analyses that estimate the spatial density of livestock holdings using different methods; on the other, to show that by combining different data sources - the 2009/10 Uganda National Panel Survey (UNPS) and the 2008 Uganda National Livestock Census (UNLC) - and applying the Small Area Estimation (SAE) technique, it is possible to provide a finer spatial disaggregation and representation of missing livestock measures in the census. First, we combine our livestock population and density figures with those from the UNLC. Second, we fit an estimation model of livestock income and share on the UNPS to generate an out-of-sample prediction of the missing information in the UNLC, mapping livestock income and share at the local level. Our results suggest that the integrated use of multiple data sources, such as household surveys, censuses, and administrative data, together with spatial analysis techniques, such as SAE, can provide reliable, coherent, and location-specific insights to guide policy and investment. This work shows a useful method that allows for a reliable spatial livestock analysis, whenever sectorial databases offer greater coverage of the population of interest, but more limited information than specialized surveys. This method can be applied in all countries where there is a similar livestock information system, and common support between livestock census and household surveys with detailed agricultural/livestock modules. Cross-validation across data sources provides clearer insights into livestock-related policy and a better springboard for effective povertyreduction strategies.
\end{abstract}

Keywords: mapping, livestock, Uganda, Small Area Estimation

JEL Codes: R12, Q12

\section{INTRODUCTION}

Livestock ownership affects household welfare in a variety of ways, including possible direct effects on household's nutrition, disposable income, asset diversification, credit constraints, manure, traction power, savings and insurance, collateral for financial services, and consumption smoothing (Ayele and Peacock, 2003; Dore, Adair, and Popkin, 2003; Upton, 2004). The role of livestock and livestock products in household income and consumption is becoming increasingly important in developing countries as the level of development improves. The livestock sector is increasingly becoming so important that experts call the phenomenon a "livestock revolution"- a monotonic and sustained increase in livestock consumption-in

\footnotetext{
* The work benefited from comments by Alberto Zezza, Gero Carletto, Stanley Wood, Thomas Sohnesen, Ugo Pica-Ciamarra, Zhe Guo, and seminar participants at the $3^{\text {rd }}$ Advisory Committee Meeting of the Livestock Data Innovation Project and at Makerere University in Kampala, whom we thank here. Two anonymous referees provided excellent suggestions that greatly improved the paper. The usual disclaimer applies. Financial support from the World Bank through the Livestock Data Innovation Project is gratefully acknowledged.

Carlo Azzarri is Research Fellow in the Environment and Production Technology Division, IFPRI. Elizabeth Cross is Economist for Occupational Employment Statistics, U.S. Bureau of Labor Statistics. Corresponding Author: C. Azzarri E-mail: c.azzarri@cgiar.org
}

(C) Southern Regional Science Association 2016. ISSN 1553-0892, 0048-749X (online)

www.srsa.org/rrs 
developing countries as the population increases, becomes wealthier, moves to urban areas, and changes its dietary preferences (Fischer, 2003). Despite the ongoing livestock revolution, widespread recognition of the importance of the livestock sector to a household's livelihood is yet to be achieved. Estimated returns to agricultural activities typically encompass livestock, although little analysis exists on distinguishing the independent contributions of crop versus livestock sources. Because of the relatively small contribution of livestock to household income, agricultural income is usually considered as being comprised mostly by returns from cropmarketing and own consumption. But in many agriculture-based economies, where agriculture contributes significantly to economic growth - such as those in sub-Saharan Africa, ${ }^{1}$ livestock provides over half of the total agricultural output and over a third of total output across all developing countries (World Bank, 2008; Upton, 2004).

In this paper, we focus on livestock as a source of income and food. Our case study is Uganda, where agricultural data that includes livestock are relatively abundant and the proportion of rural poor holding livestock is higher (around 70 percent) than in most other SubSaharan African countries. While agricultural contribution to GDP has declined from 2004 to 2008 (from 20.6 percent to 15.6 percent), the livestock sector has grown due to the increasing demand for animal-source food (ASF) (UBOS, 2009). The fact that livestock production contributed only 1.6 percent to total $\mathrm{GDP}^{2}$ in 2008 (UBOS, 2009) should be viewed as a lower bound on the overall benefits the sector can provide to small farmers. Besides income and consumption through production, livestock offers a variety of benefits to a smallholder's livelihood $^{3}$, such as cash income, food, manure, draft power and hauling services, savings and insurance, and social status and social capital. Indeed, many of the roles that livestock plays are not usually captured in standard household surveys and national accounts. A livelihood study in three districts of Uganda shows that while income from livestock provides only one of many sources of income for rural households, people typically rank livestock as their second or third most important means of livelihood (Ashley and Nanyeenya, 2005).

To build upon the existing literature on spatially disaggregated livestock measures in Uganda (Thornton et al., 2002; Kruska et al., 2003; Wint and Robinson, 2007; Robinson et al., 2011; Shaw et al., 2006; Ministry of Agriculture et al., 2010; Benson and Mugarura, 2013), this study employs the Small Area Estimation (SAE) method used in the poverty estimation literature (Elbers, Lanjouw, Lanjouw, 2003; Hentschel, Lanjouw, Lanjouw, and Poggi, 2000; Mistiaen at al., 2002; Alderman et al., 2002; Simler and Nhate, 2005) to combine survey and census data to extend and apply this method to livestock mapping. While multi-topic household surveys provide a wide array of information, their samples are not designed for disaggregation beyond the regional and rural/urban level. On the other hand, census data are usually very limited in scope but allow for disaggregation with the highest precision. Our primary objective is to provide a much finer spatial disaggregation of livestock measure than that obtained through the use of survey data alone, and to this end we combine data from the 2009/2010 Uganda National Panel Survey (UNPS) and the 2008 Uganda National Livestock Census (UNLC) to generate

\footnotetext{
${ }^{1}$ The contribution is estimated at about 32 percent on average over the period 1993-2005.

${ }^{2}$ IGAD released a series of studies for some African countries where the role of livestock in GDP is re-estimated by rescaling the national accounts data (see Behnke, 2010; 2011). As an example, the study for Ethiopia concludes that the value of livestock's contribution to the Ethiopian Gross Domestic Product (GDP) and to the wider economy is 3.5 times higher than previous estimates.

${ }^{3}$ A smallholder is a family farm relying on a small piece of land.
}

(C) Southern Regional Science Association 2016. 
small-area estimates of household income (and its share over total income) from livestock activities. ${ }^{4}$ Those estimates are the core of this analysis, since information (livestock income and its share of total income) is not captured in the census but collected and fitted exclusively using survey data.

Our other purpose (and the novelty of our approach) is to show how SAE can be applied to livestock mapping to provide policy-makers with reliable and spatially detailed information on livestock in Uganda, given that small area estimates of poverty are being increasingly used to target anti-poverty programs both in developing (see Elbers, Lanjouw, and Lanjouw, 2003; Alderman et al., 2002; Simler and Nhate, 2005; Christiaensen et al., 2011 for examples) and developed countries (see U.S. Census Bureau, 2014; Giusti et al., 2014). As recognized by official sources, mapping and access to improved spatial information play important roles in informing government actors. Enhanced spatial information may empower citizens to demand appropriate livestock policies, advocate for alternative interventions, and exert pressure for better decision-making (Ministry of Agriculture et al., 2010). Livestock maps are used by agencies and government planners for a variety of reasons: to explore more profitable market opportunities in the livestock dairy sector, to assess the impact of livestock diseases (especially trypanosomiasis ${ }^{5}$ ), and to evaluate more intensive livestock production systems.

Beyond policy-decision support, the results of this paper demonstrate how integration of different data sets can greatly enhance spatial analysis. The latter is usually carried out by using a variety of spatial methods, while our approach takes advantage of microdata in a multivariate framework. Also, the particular livestock data environment causes the focus of this study to be Uganda, but the method can be applied to other countries with a similar livestock information system when agriculture or livestock censuses are conducted in concurrence with household surveys with detailed agriculture/livestock information. The crucial requirement is an extended base of common support between the two data sources so that the missing information in the census can be reliably proxied using statistical predictions from household survey data.

\section{ANALYTICAL METHOD}

A number of methods are used in the literature to spatially predict livestock numbers and densities, most of which are based on administrative or spatial data. The most widely used spatial and econometric techniques for livestock prediction and mapping, according to Wint and Robinson (2007), are:

- Interpolation method using Kriging techniques, which is used by some spatial software such as ArcGIS (by ESRI ${ }^{6}$ ), to interpolate intermediary values of a fitted Gaussian process;

- Logistic regression, which is used mainly to identify the presence/absence of livestock, but is not suitable for population prediction, given the underlying probabilistic process that does not model intensity;

\footnotetext{
${ }^{4}$ Livestock income includes income from the sale and barter of livestock, livestock by-products (i.e., milk, eggs, honey, etc.), net of expenses related to livestock production and livestock purchases, plus the value of household consumption of own livestock and livestock byproducts. The values of own consumption are estimated based on the food expenditure section of the questionnaire.

${ }^{5}$ Trypanosomiasis is a pathogenic disease that could infect all species of domesticated livestock throughout many of the tropical and subtropical regions of the world.

${ }^{6}$ Environmental Systems Research Institute, a firm based in Redlands, California, is an international supplier of geographic information system (GIS) software, web GIS, and geodatabase management applications.
}

(C) Southern Regional Science Association 2016. 
- Weighting techniques, which are used to allocate national figures at the subnational level, based on land and biophysical suitability;

- Methods linking domestic livestock and human densities in allocating national figures (population, production, commodities) within agro-ecological zones;

- Density prediction using raster (i.e., pixel) images of observed data and predictor variables (obtained from census reports, livestock surveys, data archives);

- Extrapolation or distribution modeling using known statistical relationships between the outcome variable (e.g., animal distribution) and a number of variables considered to proxy for the outcome.

We use micro-level data and extrapolate predictions from the survey at the spatial level at which the more precisely measured (bigger) data source (typically, the census) is representative, but when the dimension of interest is missing in the larger data source, although there are proxy variables of the missing characteristics present in the less precisely measured (smaller) survey. In these cases, a prediction model estimated on the smaller survey and predicted out-of-sample on the bigger survey through proxy variables could estimate the missing dimension of interest in the bigger survey. Among all the techniques cited above, the SAE is conceptually similar to extrapolation or distribution modeling, although it makes use of micro-level data instead of spatial/area information. Different micro-data modeling techniques are used in the present study for completeness and comparison purposes, and the SAE method appears to be the most suitable to answer our research question.

The SAE methodology for dataset-to-dataset prediction (survey-to-census in our case) comprises three steps or stages. Stage 0 (according to Mistiaen et al., 2002) involves the selection of comparable information - in terms of how the data was collected and the statistical distribution of variables - between the census and the survey. At this stage, means, standard deviations, and frequency distributions at the national and regional levels are compared across surveys and the census to check whether variables have similar distribution functions.

In stage 1, the dependent variable of interest is modeled as a function of the independent variables selected, using the equation

$$
\ln \boldsymbol{y}_{c h}=E\left(\ln \boldsymbol{y}_{c h} \mid \boldsymbol{X}_{\boldsymbol{c h}}\right)+\boldsymbol{\mu}_{\boldsymbol{c h}}=\boldsymbol{X}_{\boldsymbol{c h}}^{\prime} \boldsymbol{\beta}+\boldsymbol{\mu}_{\boldsymbol{c h}},
$$

where $\boldsymbol{y}_{\boldsymbol{c}}$ is the outcome variable for household $h$ in cluster $c ; \boldsymbol{X}$ is the vector of independent variables in both the census and the survey; and $\boldsymbol{\mu}$ is the error term.

One of the most important aspects of this stage is the specification of the error term. The model above is first estimated using OLS, weighted by survey sampling weights. Residuals from this regression serve as estimates of the overall disturbance, $\hat{\mu}_{c h}$. A portion of this disturbance is due to location-specific effects common to all households in a given cluster. Since not all clusters in the census are sampled in the survey, cluster fixed effects cannot be included in stage one. Location effects must be accounted for in the error term, and as such residuals must be decomposed into location (within-cluster means of overall residuals) and household (overall residuals net of location components) elements (Mistiaen et al., 2002).

In stage 2 the error term is decomposed, so that the linear approximation of the model becomes

$$
\ln y_{c h}=X_{c h}^{\prime} \beta+\eta_{c}+\varepsilon_{c h}
$$

(c) Southern Regional Science Association 2016. 
where $\eta$ is the cluster error and is applicable to all households in a cluster and $\varepsilon$ is the household idiosyncratic error term. The two components of the error term are assumed to be uncorrelated with each other and independent of the regressors. The location component of the error term will allow for spatial autocorrelation and the possibility of heteroskedasticity of the householdspecific error component (Simler and Nhate, 2005). Additionally, the $\mu$ error term-the unexplained location-specific component-is minimized, capturing as much variation as possible through the $X$ vector by incorporating cluster-level means from the census into the survey. This is done through estimation of a Generalized Least Squares (GLS) model that takes heteroskedasticity of the household-specific error term into account.

In the final stage, parameter estimates of stage one and the decomposed error terms of stage two are applied to the census data. The disturbance term is accounted for by bootstrapping, re-sampling, and converting from logarithms to levels, ${ }^{7}$ according to

$$
\widehat{\boldsymbol{y}}_{\boldsymbol{c h}}=e^{\left(\boldsymbol{X}_{\boldsymbol{c h}}^{\prime} * \widehat{\boldsymbol{\beta}}+\widehat{\mu_{\boldsymbol{c h}}}\right)} * E\left(e^{\widehat{\mu_{\boldsymbol{c h}}}}\right) .
$$

In each of the $n$ simulations run (in our case we set $n=100$ ), parameter estimates are drawn from the multivariate normal distribution while the variance-covariance matrix and the two disturbance terms are drawn from the distributions described by the same parameters estimated in the first stage.

It should be noted that there are two sources of error that arise from the use of this method. First, there is model error due to the parameter estimates. Second, there is idiosyncratic error from the deviation of the actual $y$ from the expected $y$ (Alderman et al., 2002). Crucial assumptions of the model are the presence of high spatial correlation between Enumeration Area (EA) and subcounty, and homogeneity of households within EAs. Yet, there could be unexplained effects that impact that error term at the subcounty level (for instance, livestock prices) and at the more local EA level (for instance, disease) that are unaccounted for in the $X_{c h}$ vector. It is important to consider that the model estimated is assumed to hold for all levels of disaggregation.

These two sources for errors could substantially impact the standard errors of the estimates under certain conditions, as demonstrated by Tarozzi and Deaton (2009) through an empirical test using Monte-Carlo simulations. Nevertheless, if one is eager to accept the area homogeneity assumption, hence that "at least some aspects of the conditional distribution of income be the same in the small area as in the larger area that is used to calibrate the imputation rule," then the bias in the standard errors calculated by the version of the SAE method (Elbers, Lanjouw, and Lanjouw, 2003) used in this paper can be considered negligible, as in most empirical applications.

Despite some literature that has found that the SAE under a linear mixed model is not efficient in the case of zero-inflated outcome variables (see Chandra and Chambers, 2011; Chandra and Sud, 2012; Pfeffermann, Terryn, and Moura, 2008; Karlberg, 2000), in this paper

\footnotetext{
${ }^{7}$ In the case of OLS and SAE, given the models estimated are in log-linear form to maximize their explanatory power, predicted values have been calculated according to the retransformation formula in Cameron and Trivedi (2010) and Duan (1983): $E\left(y_{i} \mid x_{i}\right)=\exp \left(x_{i}^{\prime} \beta\right) E\left\{\exp \left(\mu_{i}\right)\right\}$. Under the assumption of an i.i.d. error term (weaker than normality), $E\left\{\exp \left(\mu_{i}\right)\right\}=$ $\frac{1}{n} \sum_{i=1}^{n} \exp \left(\hat{\mu}_{i}\right)$. In the case of the Tobit model when the dependent variable has been log-transformed (in the case of per-capita income), the unconditional expected values have been computed according to Yen and Rosinski (2008), according to a Tobit model with two-part sample selection. We thank an anonymous referee for pointing out our mistake in an earlier version of the manuscript.
}

(c) Southern Regional Science Association 2016. 
all the regressions have also been run on the positive part of the outcome variable distribution only, and results do not show any substantial difference. ${ }^{8}$ Moreover, OLS and Tobit regression models are employed for comparison purposes, and Monte-Carlo simulations have been performed to assess the explanatory power and parameter accuracy of the SAE model estimated.

As in the case of SAE, the two models are estimated on the survey and fitted on the census. The resulting parameter estimates from the regressions are then applied to the census data to calculate the conditional mean of the left-hand-side variable given the predictors.

In the case of independently and identically distributed data, error terms with a conditional mean of zero, no extreme outliers, and homoscedastic error terms, OLS represents the best linear unbiased estimates. However, because our outcome variables contain a large number of zero observations (therefore, not normally distributed but censored), OLS does not yield consistent parameter estimates.

The second model, the Tobit model, is used when the dependent variable is only observed over some interval, such as corner solutions that are composed of positive values and a large number of observations with zero values. Our three dependent variables of interest (number of large ruminants, income from livestock activities, and share of income from livestock activities) show non-negative distributions, and have a significant number of observations with zero values, rendering their log-transformation intractable. ${ }^{9}$

The OLS model has the positive feature of being simple and easily interpretable, although it is not suitable when the response variable is discrete, with probability distribution mass at nonnegative integer values only. In our case, the outcomes of interest are also truncated, showing excess zeros. The Tobit model allows us to deal with censored variables, such as livestock holdings, share, and income, although it poses a restrictive assumption on the distribution of the error terms in the unobservable left tail.

\section{DATA}

Two datasets were used for this analysis. The 2009/2010 Uganda National Panel Survey (UNPS) collected information on 2,975 households from 322 EAs. ${ }^{10}$ By sampling design, the survey is representative at the national level, plus the strata of (i) Kampala City, (ii) Other Urban Areas, (iii) Central Rural, (iv) Eastern Rural, (v) Western Rural, and (vi) Northern Rural. Data were collected in two visits, one for each cropping season, over a twelve month period. For the purpose of the analysis, the sample was narrowed to 2,375 households, of which 521 are urban. The sample was narrowed due to 45 households having incomplete questionnaires and 555 households that moved.

\footnotetext{
${ }^{8}$ Those maps are not shown here for reason of space, but available from the authors upon request.

${ }^{9}$ When the dependent variable is a nonnegative count integer such as number of large ruminants, the Poisson model should be used. This regression model has the best fit for nonlinear, nonnegative count variables, and it relaxes the assumption of the normal distribution of error terms posed in the Tobit. However, it cannot be employed for non-count variables, such as net income from livestock and share of livestock over total net income, the outcomes of interest in this paper.

10 The Uganda Bureau of Statistics conducted a Population and Housing Census in September 2002 that covered the whole country, and provided the sampling frame for the 2005/06 Uganda National Household Survey (UNHS) from which the UNPS 2009/10 used in this paper is drawn. For the purpose of census enumeration, the country was sub-divided into 34,068 Enumeration Areas, with an average of 140 households. An EA generally does not have its own name but is known by the name of the Local Council 1 (LC1) associated with it. The EA is the lowest administrative aggregation in the country.
} 
The other dataset used, the 2008 Uganda National Livestock Census (UNLC), collected data from 964,690 rural holdings in all 80 districts of the country in a single visit during the month of February. The working sample under analysis excludes large commercial farms and is narrowed to households, consistent to the UNPS where the unit of analysis is the household, hence this analysis draws on 964,047 rural households. The census is not a full enumeration census but a sample-based one, and is representative at the district level. However, given that the average sample size at the subcounty level is adequately large (around 1,000 households), results are also reported at this lower geographic administrative level (see below).

Figure 1 shows the comparison of the share of households owning (or rearing/keeping) livestock $^{11}$ by region in the survey and the census. In each region, the average number of livestock owners is not statistically significantly different between the census and the survey. The figure also highlights the importance of livestock, as the prevalence of livestock owners in Uganda is relatively high in all regions, with a national average of around 70 percent.

\section{RESULTS}

Further exploring the importance of the livestock activities to the livelihoods of Ugandan households, Figure 2 displays the breakdown of income sources by consumption expenditure quintile. Despite a high prevalence of livestock owners, the share of net livestock income (including own-consumption of animal source food) at the national level is almost 12 percent. $^{12}$ This could signal that households rear livestock for scopes different than income generation, such as manure, draft power and hauling services, savings, and insurance, as well as social status and capital (Bebe et al., 2003; Moll, 2005; Upton, 2004).

\section{Figure 1: Share of Households Owning Livestock by Region, from 2009/10 UNPS and 2008 UNLC (with 95 Percent Confidence)}

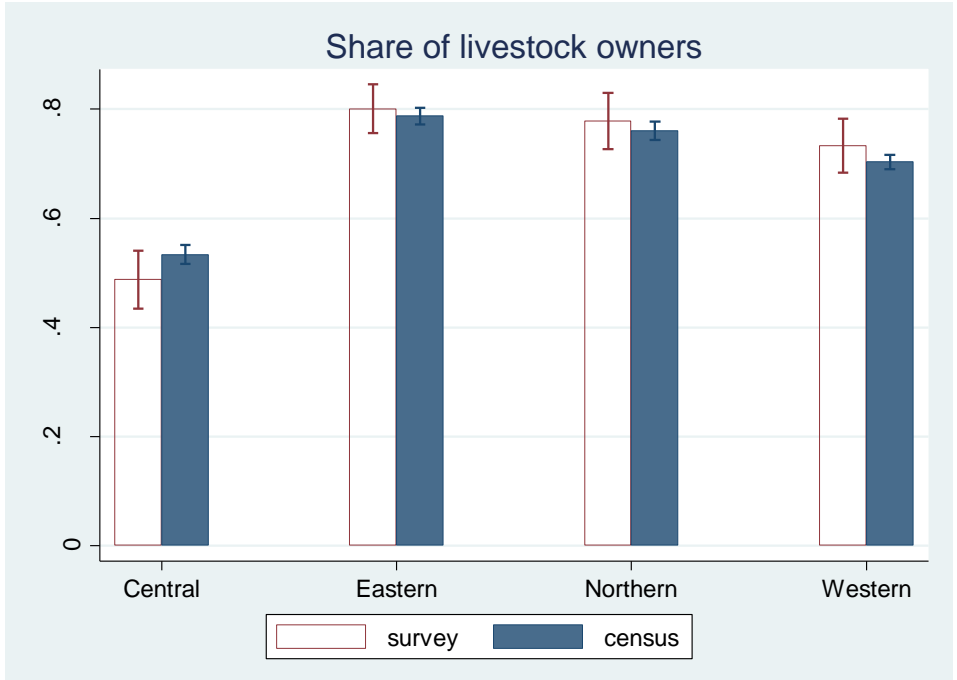

\footnotetext{
${ }^{11}$ In both the UNPS and the UNLC, the definition of livestock-owning households encompasses also households rearing, keeping, or taking care of livestock on behalf of the owners.

${ }^{12}$ Livestock income is defined as the value of sales and barter of livestock, plus the value of sales, barter and self-consumption of livestock products (such as milk, meat, eggs, honey, and so forth) minus the expenditures related to livestock production (e.g., feed, labour and veterinary services). Throughout the paper, income sources are computed and classified according to the FAO Rural Income Generating Activities (RIGA) definition and methodology (see http://www.fao.org/economic/riga/en/).
} 


\section{Figure 2: Income Decomposition by Region and Consumption Quintile}

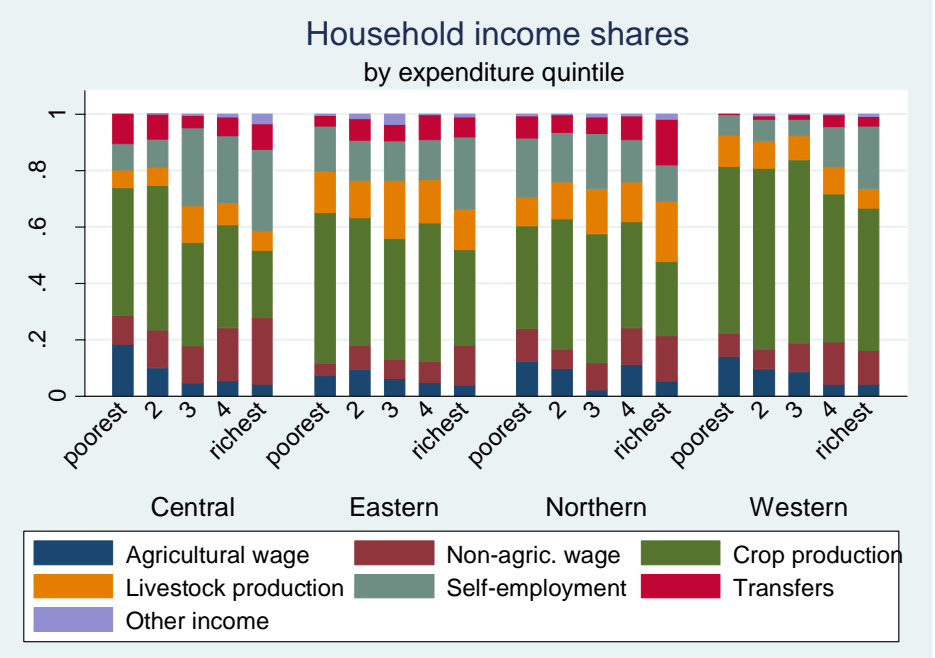

The figure shows that, overall, income composition is correlated with consumption expenditure level (a proxy of welfare), although for livestock income no stable association can be found. This finding is consistent to what the literature reports (among others, see Pica-Ciamarra et al. (2011) on a cross-country comparison of twelve developing countries). Income from crop production shows, instead, a larger share of total income in the poorest quintile, with a negative relationship with welfare. Livestock income shares differ markedly across regions, with the highest values found in the eastern and northern regions, which indeed show a greater percentage of livestock owners than the central and western regions. According to a study conducted in three districts (Mbale, Kamuli, and Mubende), livestock ownership does not seem to vary with welfare, although poorer households are more likely to have small stocks and the wealthier are more likely to own cattle. Wealthier households also keep proportionately more animals than poorer households (Ashley and Nanyeenya, 2005).

In the northern region, livestock income share seems to be positively correlated with welfare. Indeed, nomadic pastoralism constitutes the principal livelihood for many households in the northeastern part of Uganda (Benson and Mugarura, 2013). A possible explanation for this spatial pattern is due to the extremely important role of dairy cattle for children's milk consumption, especially in the Karamoja district (Stites and Mitchard, 2011). Krishna et al. (2006) show that income diversification through livestock is an important poverty-coping strategy for Ugandan households. They theorize that livestock provides an "asset stairway" out of poverty: first through investments in monogastrics, subsequently small ruminants, and finally local and then improved breeds of cattle. They also found livestock-related activities to have positively impacted the welfare of poor households.

Livestock also play a safety net role, increasing household resilience, as they are often sold in case of emergency or sudden income shortfall (Burke et al., 2007). Given that livestock play different roles, and pro-poor livestock breeds vary across regions, new research approaches providing a better understanding of spatial distribution of livestock and its contribution to livelihoods, such as the present paper, can effectively contribute to more targeted pro-poor livestock-related policy. 
The use of the UNLC can therefore support a fine-resolution livestock analysis, although the limited amount of information collected is a constraint on the number of explanatory variables included in the model. The predictors used include: land size (separately by agricultural, pasture, and other land); number of livestock heads by type (disaggregated by indigenous and exotic bulls, cows and calves; poultry; small ruminants); average weekly egg and milk production; age and gender of the household head; whether the household hired agricultural labor; dummy variables by agro-ecological zone; and Normalized Difference Vegetation Index (NDVI). ${ }^{13}$ Descriptive statistics for these variables are in Appendix A.

Three models are estimated on the 2009/10 UNPS, according to Equations (1) and (2), and are fitted on the 2008 UNLC, according to Equation (3). The first is used to test the reliability of the prediction method used. In this specification, the number of large ruminants owned are predicted and then compared to actual values in the census, both for all rural households and for those with livestock only, using different econometric models. Results of the GLS estimation are presented in Appendix B.

Figure 3 shows that the actual, as well as the predicted, spatial distribution of large ruminants from the census is very close to the predicted values using the models proposed. ${ }^{14}$ This result offers a first insight as to how SAE can be a viable and reliable method to estimate the spatial distribution of missing information through prediction. The prediction of large ruminants offers an upper bound of the reliability of the prediction methods applied to livestock-whose accuracy is further deepened in Section 4 below, given that i) the UNLC contains variables considered to be a close proxy (hence, with high explanatory power) to the number of large ruminants; ii) it is possible to compare prediction results with actual values in the census, taken as benchmark; and iii) this model has the highest explanatory power among the models estimated on other outcome variables.

The prediction model for large ruminants has a relatively high explanatory power (adjusted $R^{2}=.51$ ), while those for the share of livestock income and the per capita income from livestock both suffer from low $R^{2}$ (.25 and .05 , respectively) likely owing to omitted variables. Indeed, the major constraint in the SAE model is that regression explanatory power is bounded by availability of common information between survey and census. For this application, all the common variables between the two datasets are used, and the spatial specificity is also augmented by including the information on area covered by each agro-ecological zone and the NDVI at the subcounty level.

The northeast area of the country is ranked highest in the number of large ruminants by both actual and predicted models, although the comparison of actual versus predicted large ruminants for the whole northern region reveals substantial differences across districts. One emerging finding is that the number of large ruminants owned is not strongly correlated with livestock income and its share on household total income. While in the northeast and central areas the number of large ruminants, as well as livestock income and its share, are high, in the southern districts the latter two are both relatively low. This might occur because large ruminants

\footnotetext{
13 The NDVI assesses the degree of live green vegetation in the observed area. Negative values of NDVI (approaching -1) correspond to water. Values close to zero (-0.1 to 0.1) generally correspond to barren areas of rock, sand, or snow. Lastly, low, positive values represent shrub and grassland (approximately 0.2 to 0.4 ), while high values indicate temperate and tropical rainforests (values approaching 1). Here, the NDVI is expressed as a ten year average over the period 2000-2010 NASA (2011).

${ }^{14}$ Maps show the district distribution by quartile of actual large ruminants, so that in each category 25 percent of districts are represented. Ranges represented are the same in all maps, for ease of comparison between actual and predicted values.
}

(C) Southern Regional Science Association 2016. 
Figure 3: Actual, and Predicted Number of Large Ruminants using SAE OLS, and Tobit

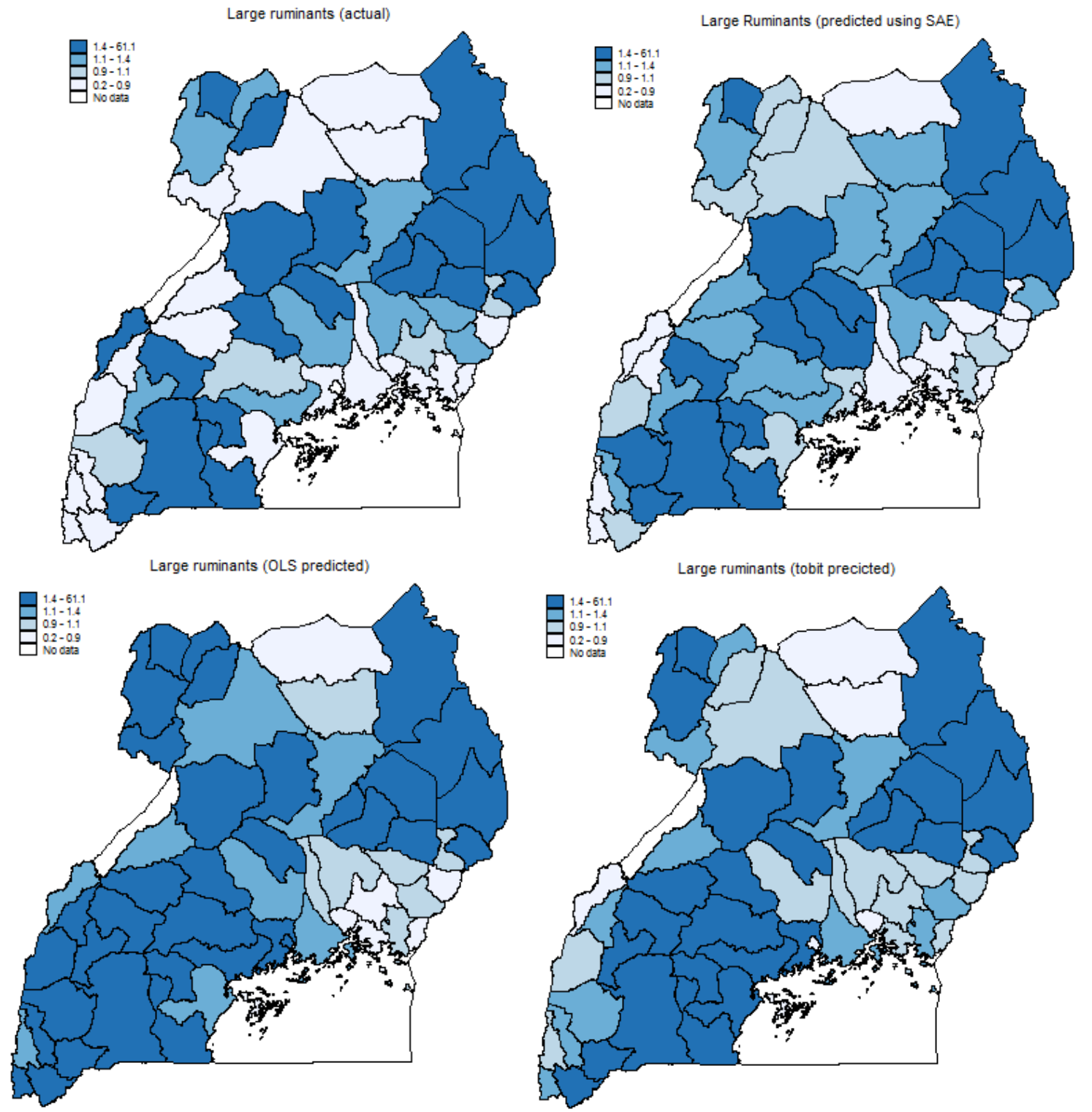

in Uganda are predominantly used by households as capital assets, and small ruminants, especially monogastrics, ${ }^{15}$ are the livestock types mostly contributing to net livestock income, given the greater costs of rearing large ruminants (Kitalyi et al., 2005).

Lu et al. (2002) also found that in the district of Kapchorwa in the eastern region, cattle are the most common livestock kept by both poor and rich farmers. However, the percentage of rich farmers keeping cattle is about double that of poor farmers, 90 percent and 45 percent, respectively. The high concentration of livestock in the northeast area of the country is also confirmed by FAO (2014), as "2008 livestock population in Karamoja was estimated at about 6 million head, representing about 19.8 percent of the national cattle (2.3 million head); 16.3 percent of the goats $(2.0$ million head) and 49.4 percent of the sheep ( 1.7 million head)." Also, livestock density appears to be predominant in the region, given that "at an overall average of

${ }^{15}$ Monogastrics are organisms with a simple single-chambered stomach, such as pigs, chickens, ducks, and rabbits.

(C) Southern Regional Science Association 2016. 


\section{Figure 4: Density of Large Ruminants: Actual from Survey and Census, and Predicted from Census}
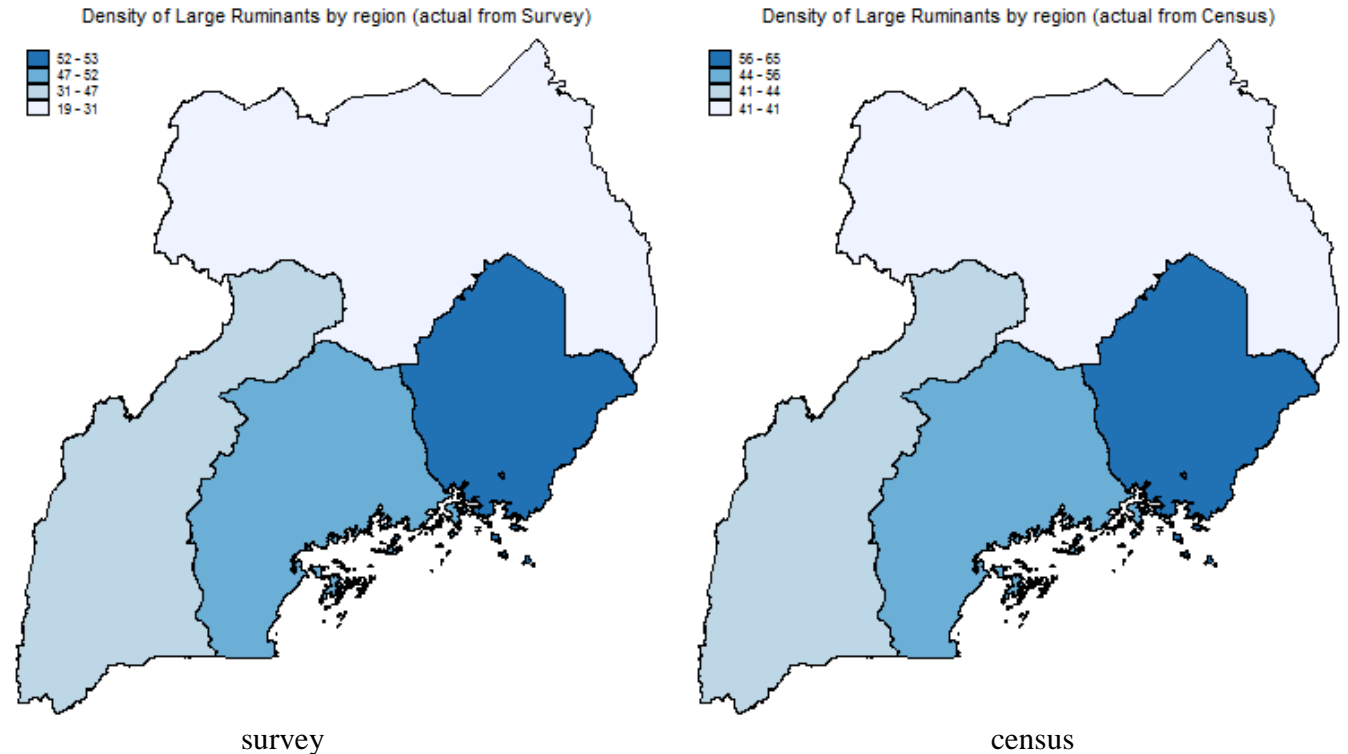

census
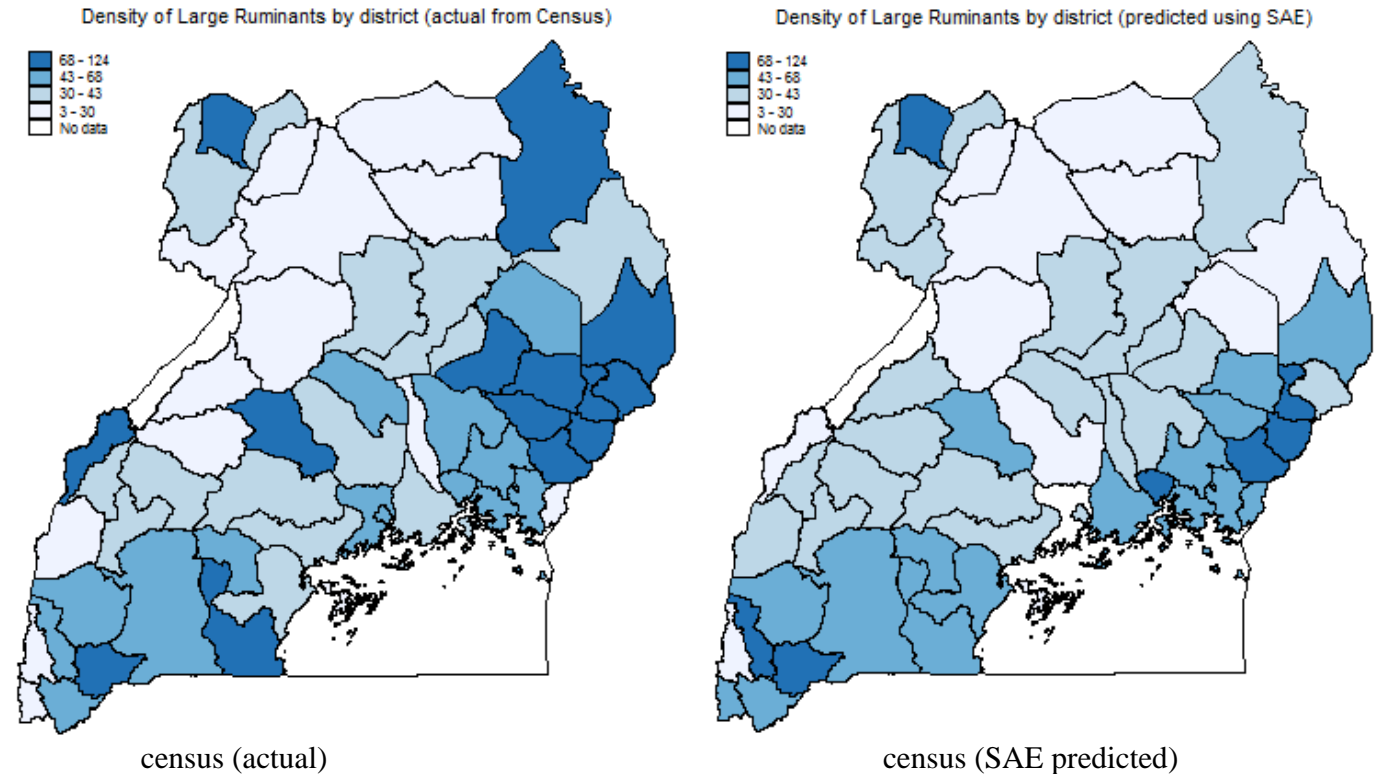

1.92 TLUs per hectare of grazing area, the stocking rates estimates are extremely high" (FAO, 2014). ${ }^{16}$

Figure 4 displays the actual densities (number of livestock per square kilometer) of large ruminants from the survey and the census, as well as the predicted densities from survey to the census using the SAE technique. Some important elements emerge. First, the survey map in

\footnotetext{
${ }^{16}$ However, the same report warns that "livestock population estimates for 2014 are significantly lower than the UBOS 2008 estimates. The estimated reduction of about 70 percent conform to information from key informants and recent reports regarding the significant losses suffered by most herders during the protected kraals system. Accordingly, Mission's estimates of stocking rate reduction from 1.92 to 0.50 TLUs per hectare of grazing resources between 2008 and 2014 are consistent with the observation of abundant availability of pasture and good body condition of all livestock types and classes during Mission's transects."
} 
Figure 4 (by region, the representative stratum of the UNPS) masks very different distributions once disaggregated to the district level through the census. Second, the density range is narrower in the survey than in the census, as in the former the range is just four values, one for each region. Indeed, these values are just the regional averages of district values of the right map. Third, and foremost, the census map is more meaningful for targeting purposes to policy-makers.

While the density of large ruminants in the census resembles the distribution from the survey, the model fitted on the log of per capita livestock income in PPP is less able to predict missing information into the census (see Appendix C). The low explanatory power of the livestock income model might be due to the fact that 46 percent of rural Ugandan households do not show any livestock income, despite 70 percent of rural households being livestock owners. Figure 5 shows maps from the survey and the census for the estimated model. ${ }^{17}$

It is interesting to note that while in the northeast region there is the highest number and concentration of large ruminants associated with high return from livestock activities, the same is less true in the central and southern areas of the country. Indeed, relatively higher income is associated with a low number and density of large ruminants in the central areas, something suggesting that households derive their income from other livestock types. Conversely, they do not seem to monetarily benefit from cattle in the Southern region, despite their high number and density. Here, two factors may be at play: the role of livestock as precautionary saving or social status, and the likely underreporting of livestock, especially in conflict-affected areas in the northern region, due to a variety of reasons (e.g., attempt to appear poorer due to fear of losing eligibility for public assistance or taxation and concern over possible retaliation or robbery). ${ }^{18}$

\section{Figure 5: Per Capita Livestock Income (PPP): Actual from Survey (left) and Predicted to Census (left)}

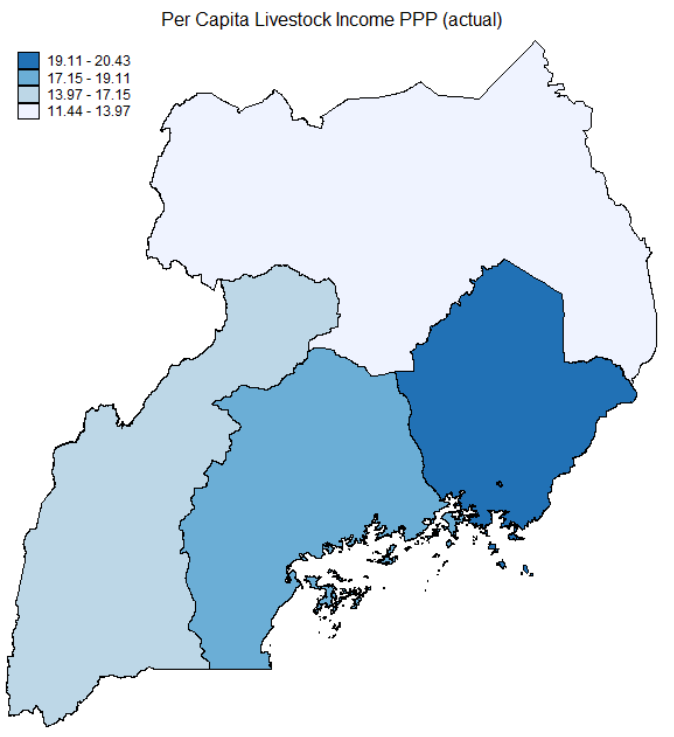

survey

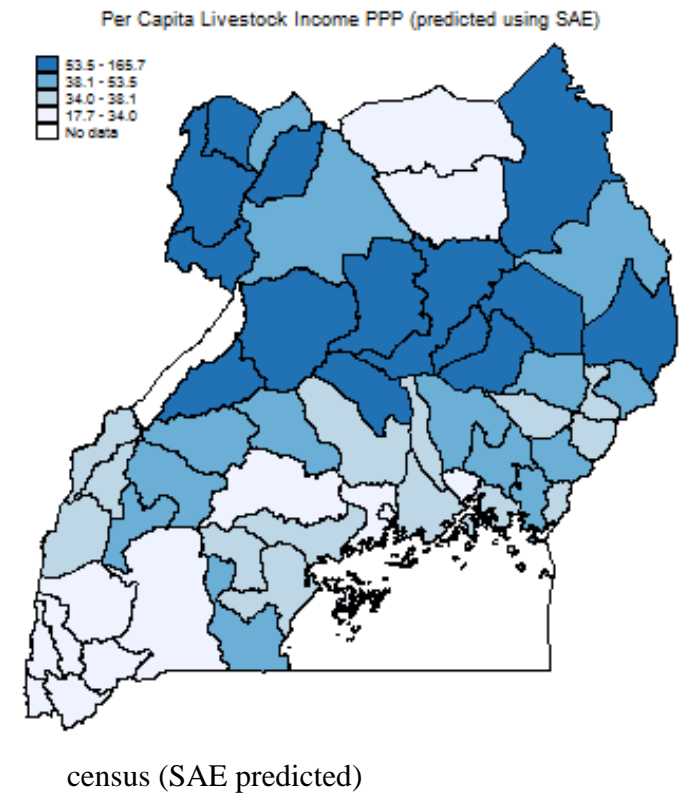

census (SAE predicted)

\footnotetext{
${ }^{17}$ See footnote 4 on the predicted value of a log-transformed dependent variable in linear models.

18 Ashley and Nanyeenya (2005) point out that "rather than keeping livestock for the relative narrow contribution of income alone, most livestock-keepers in Uganda keep their livestock for the multiple contributions they make to their livelihoods", offering a comprehensive review of the most common strategies.
}

(C) Southern Regional Science Association 2016. 
Figure 6: Share of Income from Livestock: Actual (left) and Predicted to Census (right)
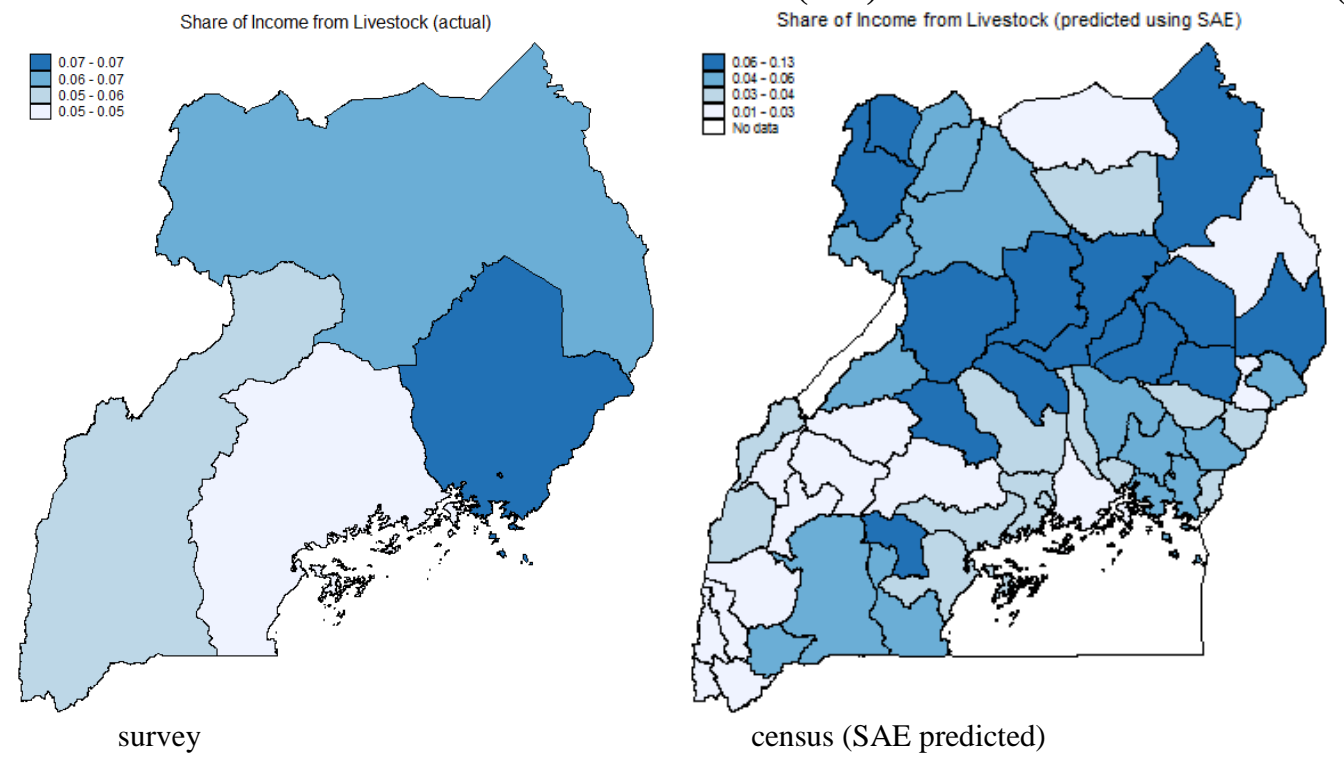

Finally, the analysis of the predicted income share from livestock at the district level yields unsurprising results in Figure 6, similar to those for income (see Appendix D for the model estimated). In almost all districts where livestock income is relatively higher, its share is also higher. Moreover, findings hold regardless of the method used, ${ }^{19}$ and this reinforces the argument that it is the lack of timely, reliable, and comprehensive survey and census data that is the constraining factor in addressing policy at the local level more than advancement in spatial data analysis.

\section{ACCURACY AND PRECISION}

By construction, the approximated error of our estimates is proportional to the sampling error of the survey, that of the census, plus the simulation error of the bootstrapped predicted values (see Equation 3). In turn, the predicted values depend strictly on the explanatory power of the model, and this last factor bears the highest effect on the accuracy of the estimated values. Should the model be fitted using more explanatory variables (common to the survey and census) and on a sample with higher size, its goodness-of-fit would greatly increase. ${ }^{20}$ As mentioned above, the specification in this paper uses the maximum number of common variables, and squared terms are also employed to maximize the portion of the variance explained by the model. To assess the explanatory power and the accuracy of the parameters of our SAE model, the actual and the SAE-predicted number of large ruminants based on the National Livestock Census are plotted in Figure 7. Treating the statistics from the NLC as the true distribution by subcounty, it is possible to realize how close the actual versus the predicted values are, as the linear fit (green line on the graph) is almost overlapping with the plotted $45^{\circ}$ line. About 90 percent of the subcounties (those with less than five large ruminants) show an average number of two ruminants, and for them the error in the prediction is particularly low, increasing as the average number of large ruminants increases (similar correlation analysis can be found in You, Wood, and Wood-Sichra, 2009; You and Wood, 2005, 2006).

\footnotetext{
${ }^{19}$ Maps using OLS and Tobit, are reported in Appendix E and F (for livestock income and it share on total income, respectively)

${ }^{20}$ Simulations were conducted using different numbers $(n)$ of bootstrap replications, and results pointed to a statistical invariance of the average of the simulated values for $n>50$.
}

(C) Southern Regional Science Association 2016. 
Figure 7: Actual and Predicted Number of Large Ruminants

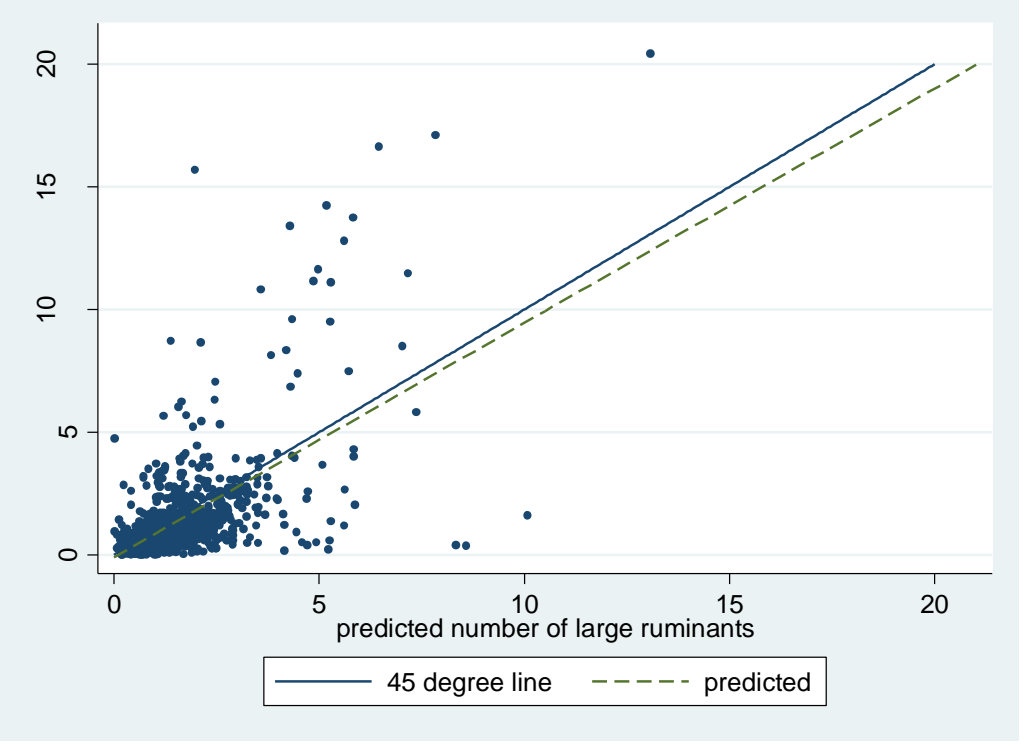

To look at the precision of the fitted values, for each value by district shown on the maps in Figure 5 and Figure 6, the corresponding value of the coefficient of variation (CV) was calculated in Figure $8 .{ }^{21}$ Overall, the precision of the estimates is low in the northern regions, relatively higher in the western region for predicted large ruminants and livestock income, and in the eastern region for the share of livestock income. This pattern is fully consistent with the difference in the $R^{2}$ across regions and models: the higher the $R^{2}$, the lower the CVs.

Figure 8. Coefficient of Variation for the Two Predicted Variables (Livestock Owners Only)
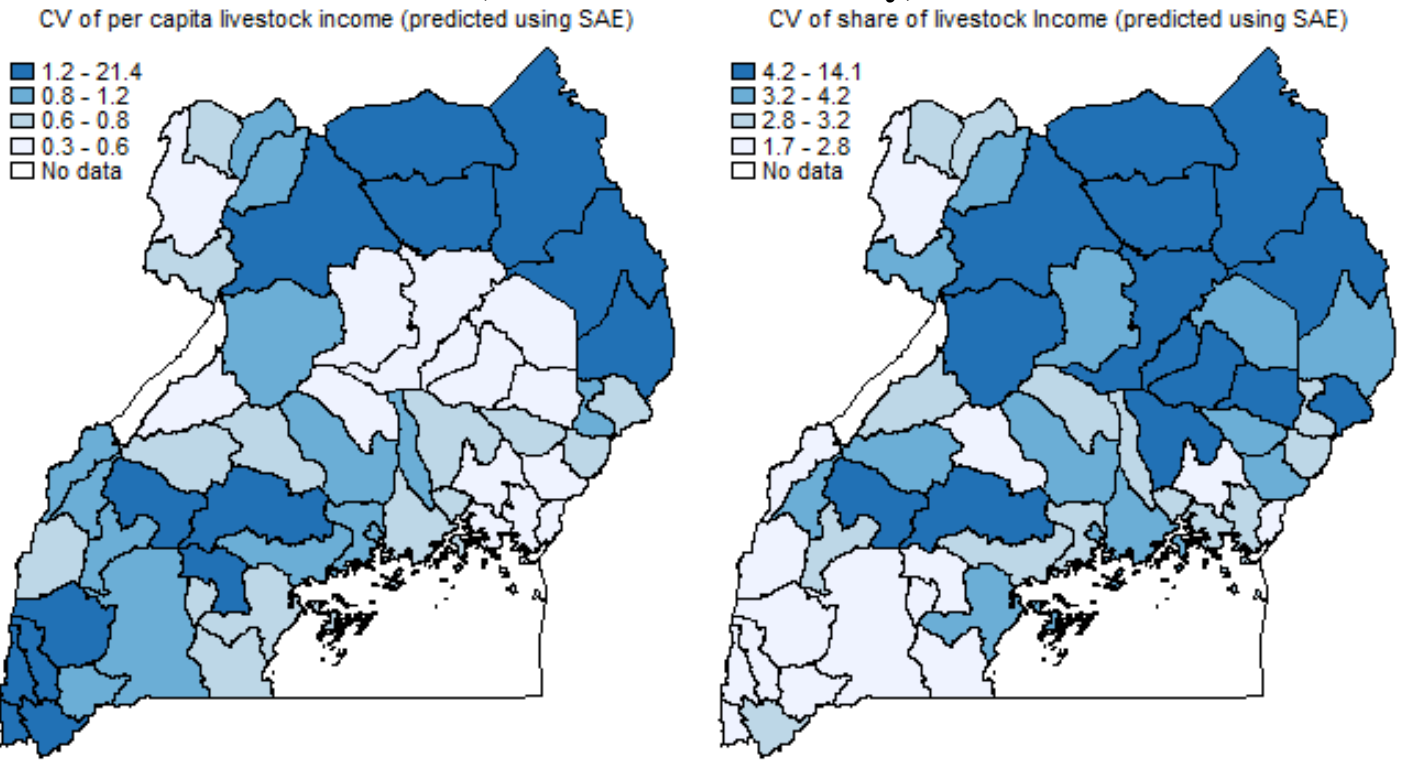

\footnotetext{
${ }^{21}$ In addition, standard deviations by district have been also computed, although for better comparability and reason of space only maps of CV are shown here (maps of standard deviations are available from the authors upon request).

(C) Southern Regional Science Association 2016.
} 
Maps thus far show district-level findings only, as this is the geographical stratification represented in the 2008 National Livestock Census. Maps at the subcounty level are also produced (see Appendix G), although they are not statistically representative of the subcounty, given the sampling design of the census. But, as mentioned above, the high average number of observations by subcounty in the UNLC (around 1,000) suggests the use of maps is possible at this lower geographical level.

As further corroboration to both accuracy and precision of our model, a set of Monte Carlo simulations has been performed. First, we test our estimated model on large ruminants against the true distribution using weighted OLS, using different simulated distributions of the error terms where the first simulation draws the residual value from a normal distribution with parameters:

$$
\mu_{h} \sim N(\theta, \sigma) \text { where } \theta=\frac{1}{n} \sum_{h=1}^{n} \mu_{h} \text { and } \sigma=\sqrt{\frac{\sum_{h=1}^{n}\left(\mu_{h}-\theta\right)}{n-1}}
$$

which are mean $(\mu=0)$ and standard deviation $(\sigma=0.119)$ of the original residual of the regression fitted using the survey. Then, we control for the data generating process (DGP) of the subsequent simulations, where parameters are simulated regardless of the structure assumed by the SAE method, that is without decomposing $\mu_{h}$ into cluster-effects and household-specific effects. Indeed, our aim is to show the difference in the parameters according to different DGPs, considering that OLS disregards the spatial autocorrelation of the error terms unlike the SAE estimator (Table 1). For this exercise, the number of Monte Carlo replications performed equals the number of observations in the National Livestock Census, thereby insuring each household in the NLC is associated a random residual drawn from different normal distributions of the residuals. $^{22}$

Results show that the average values of the residuals in the OLS regressions are always higher than those using the SAE (closer to zero), for any $\sigma^{2}$. This points to a general inconsistency of the OLS regression. When the simulated error terms are used, the spatial distribution of large ruminants does not vary by district (see Figure 9 left panel compared to Figure 3's top right panel), although the unconditional simulated distribution is, overall, more dispersed than the actual empirical distribution. This finding could suggest that the OLS parameter estimates are indeed inconsistent when only a household-specific error term is simulated.

Table 1: Mean $(\mu)$ and Standard Deviation $(\sigma)$ for Parameters Drawn from SAE and OLS Error Terms (Monte Carlo, $n=964,047)$

\begin{tabular}{|c|c|c|c|c|c|c|c|c|}
\hline & \multicolumn{4}{|c|}{ OLS } & \multicolumn{4}{c|}{ SAE } \\
\cline { 2 - 9 } & \multicolumn{3}{|c|}{$\sigma^{2}$} & \multicolumn{4}{c|}{$\sigma^{2}$} \\
\cline { 2 - 9 } & 0.0000 & 1 & 20 & 80 & 0.000 & 1 & 20 & 80 \\
\hline$\mu$ & 0.219 & 0.220 & 0.227 & 0.244 & -0.045 & -0.046 & -0.046 & -0.054 \\
\hline$\sigma$ & 0.022 & 1.000 & 4.471 & 8.953 & 0.031 & 1.001 & 4.472 & 8.944 \\
\hline \hline
\end{tabular}

\footnotetext{
${ }^{22}$ A different number of replications could be chosen, resulting in discarding replications obtained if $\mathrm{n}>$ sample size, or assigning the same value of the residuals to more observations in the NLC when $n<$ sample size.
} 


\section{Figure 9: Maps of Large Ruminants and Livestock Income per Capita using Monte Carlo Simulations}
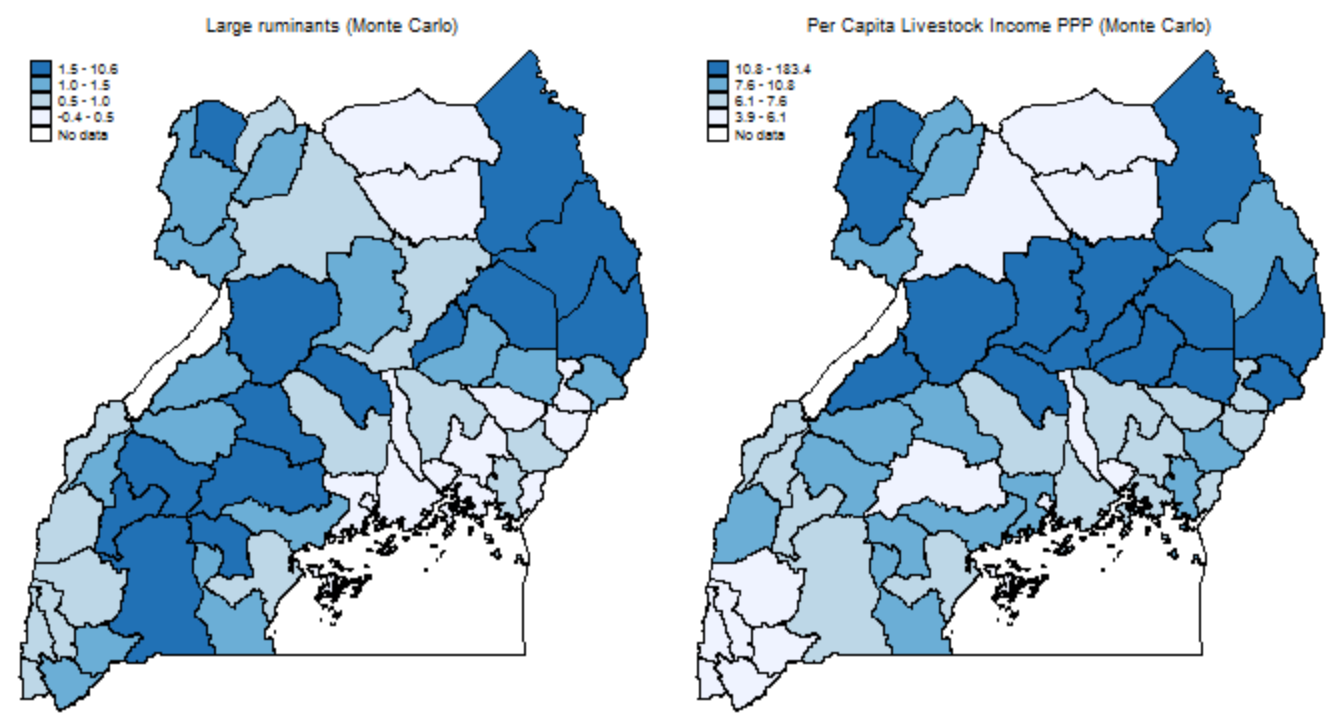

This result does not seem to vary substantially when replicating the same experiment using our preferred outcome of interest, livestock income per capita. For this case, the value of the residual assigned to each observation is the average of the 50 Monte Carlo replications drawn from a normal distribution, again with parameters equal to the original distribution of the error terms in the survey $(\mu=0, \sigma=0.119)$. Again, the spatial ranking in Figure 9 (right panel) confirms the one shown in Figure 5 (right panel), although the distribution by district shows higher variability. ${ }^{23}$

\section{CONCLUSIONS}

By fitting prediction models on micro-data and using specific assumptions on the spatial distribution of the error terms, our novel approach is to apply the Small Area Estimation to a livestock census, whereby applications thus far have been focused on welfare, poverty, and nutrition prediction. Our paper shows that combining a relatively small, multi-topic household sample survey with a specialized, big livestock database could provide a promising approach to estimate the contribution of livestock to livelihood at the household level in Uganda. Among the various econometric models tested, the SAE technique could represent a valuable tool for informing livestock policy that governments should consider. We empirically show that, using two different databases and applying the SAE method, the spatial disaggregation of missing livestock measures in the census can be improved and used in policy targeting, as our survey-tocensus imputation approach yields a finer geographical disaggregation than what is obtained using the survey data alone. This is particularly important for policy decisions as there is the constant need for various actors (e.g., donors, investment banks, policy-makers) to provide more spatially specific, tailored findings. Our results are also consistent with the literature and are stable regardless of the econometric model used, strengthening their reliability.

Estimation results show that the northeast area of the country is ranked highest in the number of large ruminants, although the comparison of actual versus predicted large ruminants

${ }^{23}$ Maps at the sub-count level are reported in Appendix G.

(C) Southern Regional Science Association 2016. 
for the whole northern region reveals substantial differences across districts. One important finding is that the number of large ruminants owned is not strongly correlated with livestock income and its share on household total income. While in the northeast and central areas the number of large ruminants, as well as livestock income and its share, are high, in the southern districts the latter two are both relatively low. Indeed, the relatively higher income is associated with a low number and density of large ruminants in the central areas, suggesting that households derive their income from other livestock types. Conversely, they do not seem to monetarily benefit from cattle in the southern region, despite their high number and density. Here, different factors may be at play: the role of livestock as precautionary saving or social status, the specific role of large ruminants as capital assets rather than income-generation resources, and the likely underreporting of livestock, especially in conflict-affected areas in the northern region, due to a variety of reasons.

This spatial pattern of our results confirms earlier studies that state the northeastern area of Uganda is characterized by extensive cattle-dominated farming systems, being part of the socalled cattle belt, stretching across the central region from the base of the highlands into the southwest through the area around Lake Kyoga. Our study underlines the importance of spatially explicit maps at the finest resolution level possible, here provided at region, district, and finally subcounty levels. A careful analysis of the maps at an increasingly finer disaggregation level can give important warnings about the costs due to miss-targeting. In fact, they can be remarkably high to the extent that livestock policy (such as veterinary campaigns, livestock extension services, investments in new breeds, and studies on market opportunities) targets whole regions or districts with apparently low shares of livestock. This eventual progressive misallocation (or leakage) could hit other districts or subcounties with undercoverage particularly hard, given the fixed level of funding and investments available for the sector.

The internal validity of our estimates has been tested using different econometric models and a set of Monte Carlo simulations, which suggest that OLS parameter estimates are indeed inconsistent when only a household-specific error term is simulated. The residuals in the OLS model are on average higher than those using the SAE method. This result seems to be stable regardless of the outcome of interest (large ruminants or our preferred livestock income per capita). While the spatial ranking across districts using the SAE approach confirms the method using Monte Carlo simulation, the distribution by district shows higher variability using the latter approach.

In terms of external validity and feasibility, our approach can be easily replicable and scaled to other countries with similar statistical agricultural and livestock data systems (e.g., Tanzania, Ethiopia). The crucial requirement is a relatively high common support between the survey and the census so that the missing information in the census can be reliably predicted using statistical inference from survey data, although our analysis shows that even with an agriculture-focused household survey it is possible to obtain granular and spatially robust results.

There are additional areas for potential exploration of SAE and mapping approaches for policy targeting. Mapping can be useful when combined with factors such as infrastructure, market access, land cover, soil quality, or environmental characteristics. Results of this paper suggest that national statistical agencies should aim to achieve greater coordination at the design stage between surveys and censuses so as to ensure higher common support between data sources for a more effective integration of different databases. Expanding the topics and the sample (ideally attaining full enumeration) covered in the census goes in this direction and would 
greatly refine the results, provided information is collected using similar survey instruments and data collection protocols.

\section{REFERENCES}

Alderman, Harold, Miriam Babita, Gabriel Demombynes, Nthabiseng Makhatha, and Berk Özler. (2002) "How Low Can You Go? Combining Census and Survey Data for Mapping Poverty in South Africa," Journal of African Economies, 11, 169-200.

Ashley, Steve and William Nanyeenya. (2005) "More than Income: Pro-Poor Livestock Development Policy in Uganda," in Frank Ellis and H. Ade Freeman (eds.), Rural Livelihoods and Poverty Reduction Policies. Routledge: New York, pp. 235-255.

Ayele, Zewdu and Christie Peacock. (2003) "Improving Access to and Consumption of Animal Source Foods in Rural Households: The Experiences of a Woman-Focused Goat Development Program in the Highlands of Ethiopia," Journal of Nutrition, 133, 3981S3986S.

Bebe, Bockline O., Henk M.J. Udo, Gareth J. Rowlands, and William Thorpe. (2003) "Smallholder Dairy Systems in Kenya Highlands: Breed Preferences and Breeding Practices," Livestock Production Science, 82, 117-127.

Behnke, Roy. (2011) "The Contribution of Livestock to the Ethiopian Economy - Part II," IGAD LPI Working Paper, 02(11), Odessa Centre, Great Wolford, U.K. Last accessed January 2016 at http://www.odessacentre.co.uk/uploads/3/9/1/2/39125553/igad_ethiopia_ii.pdf.

Behnke, Roy. (2010) "The Contribution of Livestock to the Economies of IGAD Member States Study Findings, Application of the Methodology in Ethiopia and Recommendations for Further Work," IGAD LPI Working Paper, 02(10), Odessa Centre, Great Wolford, U.K. Last accessed online in January 2016 at http://citeseerx.ist.psu.edu/viewdoc/download?doi=10.1.1.366.1385\&rep=rep1\&type=pdf.

Benson, Todd and Samuel Mugarura. (2013) "Livestock Development Planning in Uganda: Identification of Areas of Opportunities and Challenge," Land Use Policy, 35, 131-139.

Burke, William J., Thomas S. Jayne, H. Ade Freeman, and Patricia Kristjanson. (2007) "Factors Associated with Farm Households' Movement into and out of Poverty in Kenya: The Rising Importance of Livestock," Michigan State University International Development Working Paper, 90, East Lansing, MI. Last accessed online in January 2016 at http://ageconsearch.umn.edu/bitstream/54563/2/idwp90.pdf.

Cameron, A. Colin and Pravin K. Trivedi. (2010) Microeconometrics Using Stata. Revised Edition. Stata Press: College Station, TX.

Chandra, Hukum and Ray Chambers. (2011) "Small Area Estimation for Skewed Data in Presence of Zeros," Bulletin of the Calcutta Statistical Association, 63, 249-252.

Chandra, Hukum and Umesh C. Sud. (2012) "Small Area Estimation for Zero-Inflated Data," Communications in Statistics—Simulation and Computation, 41, 632-643.

Christiaensen, Luc, Peter Lanjouw, Jill Luoto, David Stifel. (2012) "Small Area Estimationbased Prediction Methods to Track Poverty: Validation and Applications," Journal of Economic Inequality, 10, 267-297.

C Southern Regional Science Association 2016. 
Dore, Anna R., Linda S. Adair, and Barry M. Popkin. (2003) "Low Income Russian Families Adopt Effective Behavioral Strategies to Maintain Dietary Stability in Times of Economic Crisis," Journal of Nutrition, 133, 3469-3475.

Duan, Naihua. (1983) "Smearing Estimate: A Nonparametric Retransformation Method," Journal of the American Statistical Association, 78, 605-610.

Elbers, Chris, Jean O. Lanjouw, and Peter Lanjouw. (2003) "Micro-Level Estimation of Poverty and Inequality," Econometrica, 71, 355-364.

FAO. (2014) “Livestock and Market Assessment Mission to Karamoja Region, Uganda," Special Report. Last accessed online in January 2016 at http://www.fao.org/docrep/019/I3674e/I3674e.pdf.

Fischer, Tim. (2003) “The Livestock Revolution: A Pathway from Poverty?” preface in A.G. Brown (ed.), The Livestock Revolution: A Pathway from Poverty. In proceedings of a conference held at the ATSE Crawford Fund, Parliament House: Canberra. ATSE Crawford Fund, pp. 1-2.

Giusti, Caterina, Monica Pratesi, Nikos Tzavidis, and Nicola Salvati. (2014) "Resistance to Outliers of M-Quantile and Robust Random Effects Small Area Models," Communications in Statistics-Simulation and Computation, 43, 549-568.

Hentschel, Jesko, Jean Olson Lanjouw, Peter Lanjouw, and Javier Poggi. (2000) "Combining Census and Survey Data to Trace the Spatial Dimensions of Poverty: A Case Study of Ecuador," World Bank Economic Review, 14, 147-165.

Karlberg, Forough. (2000) "Survey Estimation for Highly Skewed Populations in the Presence of Zeroes," Journal of Official Statistics, 16, 229-241.

Kitalyi, Aichi, L. Mtenga, John Morton, Anni McLeod, Philip Thornton, Andrew Dorward, and M. Saadullah. (2005) "Why Keep Livestock if You Are Poor," in Emyr Owen, Aichi Kitalyi, Nobel Jayasuriya, and Timothy Smith (eds.), Livestock and Wealth Creation, Improving the Husbandry of Animals Kept by Resource-poor People in Developing Countries. Nottingham University Press: Nottingham, U.K., pp. 13-27.

Krishna, Anirudh, Daniel Lumonya, Milissa Markiewicz, Firminus Mugumya, Agatha Kafuko, and Jonah Wegoye. (2006) "Escaping Poverty and Becoming Poor in 36 Villages of Central and Western Uganda," Journal of Development Studies, 42, 346-370.

Kruska, Russell L., Robin S. Reid, Philip K Thornton, Norbert Henninger, and Patti M. Kristjanson. (2003) "Mapping Livestock-oriented Agricultural Production Systems for the Developing World," Agricultural Systems, 77, 39-63.

Lu, Yuelai, John McDonagh, Onesmus Semalulu, Michael Stocking, and Stanley Nkalubo. (2002) "Bridging Research and Development in Soil Management: Matching Technical Options with Local Livelihoods," in Wang Lianxiang, Wu Deyi, Tu Xiaoning, and Nie Jing (eds.), Proceedings of the 12th ISCO Conference, Vol. 3: Technology and Method of Soil and Water Conservation. Last accessed January 2016 at http://tucson.ars.ag.gov/isco/isco12/volume_3.html.

Ministry of Agriculture, Animal Industry and Fisheries, Uganda; Uganda Bureau of Statistics; Food and Agriculture Organization of the United Nations; International Livestock Research Institute; and World Resources Institute. (2010) Mapping a Better Future:

C Southern Regional Science Association 2016. 
Spatial Analysis and Pro-Poor Livestock Strategies in Uganda. World Resources Institute: Washington, D.C.

Mistiaen, Johan, Berk Özler, Tiaray Razafimanantena, and Jean Razafindravonona. (2002) "Putting Welfare on the Map in Madagascar," Africa Region Working Paper Series, 34, The World Bank, Washington, D.C. Last accessed online in January 2016 at http://siteresources.worldbank.org/DEC/Resources/putwelfareondamap.pdf.

Moll, Henk A.J. (2005) "Costs and Benefits of Livestock Systems and the Role of Market and Nonmarket Relationships," Agricultural Economics, 32, 181-193.

NASA. (2011) "Land Processes Distributed Active Archive Center (LP DAAC): MODIS Vegetation Indices version 5," USGS/Earth Resources Observation and Science (EROS) Center: Sioux Falls, SD.

Pfeffermann, Danny, Bénédicte Terryn, and Fernando A. S. Moura. (2008) "Small Area Estimation under a Two-part Random Effects Model with Application to Estimation of Literacy in Developing Countries," Survey Methodology, 34, 235-249.

Pica-Ciamarra, Ugo, Luca Tasciotti, Joachim Otte, and Alberto Zezza. (2011) "Livestock Assets, Livestock Income and Rural Households Cross-Country Evidence from Household Surveys," ESA Working Paper, 11(17), Agricultural Development Economics Division, FAO: Rome. Last accessed online in January 2016 at https://www.openknowledge.worldbank.org/bitstream/handle/10986/17890/866470WP0P AP0L00Box385182B00PUBLIC0.pdf.

Robinson, Timothy, Philip Thornton, Gianluca Franceschini, Russ Kruska, Federica Chiozza, An Notenbaert, Giuliano Cecchi, Mario Herrero, Michael Epprecht, Steffen Fritz, Liangzhi You, Giulia Chonchedda, and Linda See. (2011) Global Livestock Production Systems. FAO and ILRI: Rome.

Shaw, Alexandra, Guy Hendrickx, Marius Gilbert, Raffaele Mattioli, Victorin Codjia, Balabadi Dao, Oumar Diall, Charles Mahama, Issa Sidibé, and William G.R. Wint. (2006) "Mapping the Benefits: A New Decision Tool for Tsetse and Trypanosomiasis Interventions," Research Report, Department for International Development, Animal Health Programme, Centre for Tropical Veterinary Medicine, University of Edinburgh, UK and Programme Against African Trypanosomiasis, FAO: Rome. Last accessed online in January 2016 at http://www.fao.org/ag/againfo/programmes/en/paat/documents/papers/Paper_2006.pdf.

Simler, Kenneth R. and Virgulino Nhate. (2005) "Poverty, Inequality, and Geographic Targeting: Evidence from Small-Area Estimates in Mozambique," FCND Discussion Paper, 192, IFPRI: Washington, D.C.

Stites, Elizabeth and Emily Mitchard. (2011) Milk Matters in Karamoja: Milk in Children's Diets and Household Livelihoods. Feinstein International Center, Tufts University: Medford, MA. Last accessed online in January 2016 at http://www.fao.org/fileadmin/user_upload/drought/docs/MM-Karamoja.pdf.

Tarozzi, Alessandro and Angus Deaton. (2009) "Using Census and Survey Data to Estimate Poverty and Inequality for Small Areas," Review of Economics and Statistics, 91, 773792

(c) Southern Regional Science Association 2016. 
Thornton, Peter K., Russell L. Kruska, Norbert Henninger, Patti M. Kristjanson, Robin S. Reid, Fred Atieno, Andrew N. Odero, and Thomas Ndegwa. (2002) Mapping Poverty and Livestock in the Developing World. International Livestock Research Institute: Nairobi, Kenya.

Uganda Bureau of Statistics (UBOS). (2009) Statistical Abstract. Kampala, Uganda.

Upton, Martin. (2004) "The Role of Livestock in Economic Development and Poverty Reduction," PPLPI Working Paper 10, Pro-Poor Livestock Policy Initiative (PPLPI), FAO: Rome. Last accessed online in January 2016 at http://ageconsearch.umn.edu/bitstream/23783/1/wp040010.pdf.

U. S. Census Bureau. (2014) Small Area Income and Poverty Estimates. Last accessed January 2016 at http://www.census.gov/did/www/saipe/

Wint, William G.R. and Timothy P. Robinson. (2007) Gridded Livestock of the World 2007. FAO: Rome, Italy. Last accessed online in January 2016 at ftp://ftp.fao.org/docrep/fao/010/a1259e/a1259e00.pdf.

World Bank. (2008) World Development Report 2008-Agriculture for Development. Washington, DC.

Yen, Steven T. and Jan Rosinski. (2008) "On the Marginal Effects of Variables in the LogTransformed Sample Selection Models,” Economics Letters, 100, 4-8.

You, Liangzhi, Stanley Wood, and Ulrike Wood-Sichra. (2009) "Generating Plausible Crop Distribution Maps for Sub-Saharan Africa using a Spatially Disaggregated Data Fusion and Optimization Approach,” Agricultural Systems, 99, 126-140.

You, Liangzhi and Stanley Wood. (2006) "An Entropy Approach to Spatial Disaggregation of Agricultural Production," Agricultural Systems, 90, 329-347.

. (2005) "Assessing the Spatial Distribution of Crop Production using a Cross-Entropy Method," International Journal of Applied Earth Observation and Geoinformation, 7, 310-323.

(c) Southern Regional Science Association 2016. 


\section{APPENDIX A}

\section{Summary Statistics for Variables from Survey and Census}

\begin{tabular}{|c|c|c|c|c|c|c|c|c|}
\hline \multirow[b]{2}{*}{ Variable } & \multicolumn{4}{|c|}{ survey } & \multicolumn{4}{|c|}{ census } \\
\hline & Mean & Std. Dev & Min & Max & Mean & Std. Dev & Min & Max \\
\hline Hired labor* & 0.0692 & 0.2538 & 0 & 1 & 0.0361 & 0.1866 & 0 & 1 \\
\hline Agricultural Land & 1.4297 & 1.7029 & 0 & 22.46 & 0.5448 & 1.1248 & 0 & 129.5 \\
\hline Pasture & 0.3134 & 4.2924 & 0 & 133.55 & 0.5869 & 6.3135 & 0 & 404.69 \\
\hline Other Land & 0.1324 & 2.8798 & 0 & 121.41 & 0.064 & 0.7186 & 0 & 242.81 \\
\hline Indigenous Bulls & 0.3962 & 1.4853 & 0 & 40 & 0.6218 & 2.4312 & 0 & 78 \\
\hline Indigenous Cows & 0.9094 & 3.5142 & 0 & 80 & 1.1522 & 4.6532 & 0 & 130 \\
\hline Indigenous Calves & 0.4284 & 1.4868 & 0 & 23 & 0.4165 & 1.7483 & 0 & 50 \\
\hline Exotic Bulls & 0.0525 & 0.4301 & 0 & 10 & 0.0301 & 0.4514 & 0 & 70 \\
\hline Exotic Cows & 0.1877 & 1.3467 & 0 & 30 & 0.1148 & 1.573 & 0 & 121 \\
\hline Exotic Calves & 0.1405 & 1.0278 & 0 & 22 & 0.0433 & 0.6247 & 0 & 52 \\
\hline Goats & 2.083 & 3.6451 & 0 & 70 & 2.0117 & 4.7151 & 0 & 96 \\
\hline Sheep & 0.4314 & 1.9538 & 0 & 33 & 0.696 & 4.1646 & 0 & 113 \\
\hline Pigs & 0.4365 & 1.2419 & 0 & 15 & 0.4398 & 1.3278 & 0 & 64 \\
\hline Chickens & 5.3391 & 8.3603 & 0 & 166 & 5.3873 & 10.735 & 0 & 562 \\
\hline Turkeys & 0.0713 & 0.6038 & 0 & 10 & 0.0728 & 0.6739 & 0 & 40 \\
\hline Ducks & 0.2005 & 1.3352 & 0 & 25 & 0.1865 & 1.2066 & 0 & 41 \\
\hline Other Birds & 0.0987 & 1.0903 & 0 & 24 & 0.0962 & 1.0298 & 0 & 100 \\
\hline Rabbits & 0.0606 & 0.6576 & 0 & 15 & 0.0419 & 0.5305 & 0 & 30 \\
\hline Donkeys & 0.0123 & 0.2107 & 0 & 6 & 0.0419 & 0.5444 & 0 & 40 \\
\hline Bees & 0.1319 & 1.5963 & 0 & 50 & 0.0898 & 0.8457 & 0 & 50 \\
\hline Eggs & 1.63 & 54.001 & 0 & 2326.2 & 1.6134 & 10.718 & 0 & 1750 \\
\hline Milk & 3.4793 & 18.777 & 0 & 346.15 & 2.6582 & 21.706 & 0 & 3780 \\
\hline Age of Head & 47.295 & 15.162 & 14 & 100 & 41.925 & 15.365 & 12 & 99 \\
\hline Head is Female* & 0.2863 & 0.4522 & 0 & 1 & 0.2729 & 0.4454 & 0 & 1 \\
\hline NDVI Mean & 6439.9 & 804.68 & 3506.2 & 8169.5 & 6370.3 & 866.03 & 2950.7 & 8169.5 \\
\hline $\begin{array}{r}\text { NDVI Standard } \\
\text { Deviation }\end{array}$ & 323.1 & 383.8 & 40.574 & 3061.5 & 319.19 & 400.83 & 0 & 3061.5 \\
\hline Tropic Cool Humid & 46.26 & 91.116 & 0 & 832 & 40.073 & 101.63 & 0 & 832 \\
\hline Tropic Warm Humid & 130.38 & 181.76 & 0 & 1823 & 136.82 & 246.43 & 0 & 3196 \\
\hline Tropic Cool Subhumid & 38.912 & 116.96 & 0 & 815 & 39.557 & 144.47 & 0 & 1902 \\
\hline Tropic Warm Subhumid & 14.27 & 76.471 & 0 & 770 & 18.098 & 109.07 & 0 & 1950 \\
\hline $\mathrm{N}=$ & \multicolumn{4}{|c|}{1865} & \multicolumn{4}{|c|}{953455} \\
\hline
\end{tabular}




\section{APPENDIX B}

Table B.1: Results of GLS Estimation of Number of Large Ruminants, All Rural Households

\begin{tabular}{|c|c|c|c|c|c|}
\hline & National & Central & Eastern & Northern & Western \\
\hline & $3.7615 * * *$ & $5.2239 * * *$ & $1.0685 * *$ & 1.0321 & $5.4623 * * *$ \\
\hline 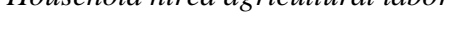 & -0.398 & -0.7837 & -0.4559 & -1.0008 & -0.64 \\
\hline \multirow{2}{*}{ Agricultural Land (Hectares) } & $0.2160 * * *$ & -0.1233 & $0.4995 * * *$ & $0.1834 *$ & 0.0434 \\
\hline & -0.0579 & -0.142 & -0.0527 & -0.1055 & -0.1367 \\
\hline \multirow{2}{*}{ Pasture Land (Hectares) } & $0.2548 * * *$ & $0.8797 * * *$ & -0.3264 & 1.0701 & $0.1129 * * *$ \\
\hline & -0.0255 & -0.0536 & -0.2164 & -1.1688 & -0.032 \\
\hline \multirow{2}{*}{ Other Land (Hectares) } & $-0.1451 * * *$ & 0.9781 & $0.1005^{* * *}$ & 0.3609 & -0.0296 \\
\hline & -0.0339 & -0.7347 & -0.0221 & -0.368 & -0.692 \\
\hline \multirow{2}{*}{ Goats } & $0.2034 * * *$ & $0.2309 * *$ & $0.246 * * *$ & $0.4083 * * *$ & 0.0236 \\
\hline & -0.0272 & -0.0917 & -0.0428 & -0.0502 & -0.0352 \\
\hline \multirow{2}{*}{ Sheep } & $0.7749 * * *$ & $0.5439 * * *$ & $0.2721 * * *$ & $0.3832 * * *$ & $0.6110 * * *$ \\
\hline & -0.0525 & -0.1199 & -0.0935 & -0.0826 & -0.1023 \\
\hline \multirow{2}{*}{ Pigs } & $0.1545^{* *}$ & $0.4284 * * *$ & $0.2438 * * *$ & 0.0848 & $-0.2691 * *$ \\
\hline & -0.0707 & -0.1064 & -0.0763 & -0.4424 & -0.1358 \\
\hline \multirow{2}{*}{ Chickens } & $0.0510 * * *$ & $0.0590 *$ & 0.0159 & 0.0418 & $0.0938 * * *$ \\
\hline & -0.0136 & -0.0329 & -0.0109 & -0.0295 & -0.0331 \\
\hline \multirow{2}{*}{ Turkeys } & 0.1215 & 0.4723 & 0.0384 & 0.2805 & -0.1739 \\
\hline & -0.1543 & -0.421 & -0.0895 & -0.7045 & -0.6513 \\
\hline \multirow{2}{*}{ Ducks } & -0.0502 & -0.0547 & -0.0029 & -0.0616 & -0.0297 \\
\hline & -0.0663 & -0.0907 & -0.0931 & -0.1247 & -0.2927 \\
\hline \multirow{2}{*}{ Other Birds } & -0.0213 & -0.7182 & -0.0673 & 0.0935 & \\
\hline & -0.0868 & -0.5359 & -0.0513 & -0.1823 & \\
\hline \multirow{2}{*}{ Rabbits } & -0.1049 & -0.2926 & -0.2129 & -0.1287 & 0.0031 \\
\hline & -0.1492 & -0.2718 & -0.2299 & -0.4299 & -0.2003 \\
\hline \multirow{2}{*}{ Bees } & 0.0488 & & 0.15541 & -0.0043 & -0.0577 \\
\hline & -0.0588 & & -0.1733 & -0.0996 & -0.0668 \\
\hline \multirow{2}{*}{ Average Weekly Egg Production } & $-0.0038 * * *$ & $-0.0051 * *$ & -0.0288 & 0.0738 & 0.041 \\
\hline & -0.0014 & -0.0025 & -0.0326 & -0.1667 & -0.037 \\
\hline \multirow{2}{*}{ Average Weekly Milk Production } & $0.0678 * * *$ & $0.0851 * * *$ & $0.1001 * * *$ & $0.1355 * * *$ & $0.0998 * * *$ \\
\hline & -0.0062 & -0.0145 & -0.0075 & -0.0274 & -0.0086 \\
\hline \multirow{2}{*}{ Age of Head } & 0.0079 & -0.0019 & 0.0088 & 0.0182 & $0.0201 *$ \\
\hline & -0.0061 & -0.0122 & -0.0065 & -0.0122 & -0.0108 \\
\hline \multirow{2}{*}{ Head is Female } & $-0.3902 *$ & $-1.2453 * * *$ & -0.2352 & -0.6343 & 0.0789 \\
\hline & -0.2059 & -0.4036 & -0.2121 & -0.4041 & -0.3652 \\
\hline \multirow{2}{*}{ NDVI Mean } & -0.0001 & 0.0001 & 0 & -0.0001 & 0.0004 \\
\hline & -0.0001 & -0.0004 & -0.0002 & -0.0004 & -0.0003 \\
\hline
\end{tabular}


Table B.1 (Continued): Results of GLS Estimation of Number of Large Ruminants, All Rural Households

\begin{tabular}{|c|c|c|c|c|c|}
\hline & National & Central & Eastern & Northern & Western \\
\hline \multirow{2}{*}{ NDVI Standard Deviation } & 0.0001 & 0.0004 & $0.0005^{*}$ & -0.0006 & -0.0003 \\
\hline & -0.0003 & -0.0008 & -0.0003 & -0.0013 & -0.0006 \\
\hline \multirow{2}{*}{ AEZ-Tropic Cool Humid } & $0.0087 * * *$ & $0.0058 * * *$ & $0.0088 *$ & -0.0082 & $0.0078 * * *$ \\
\hline & -0.0011 & -0.0015 & -0.0046 & -0.0058 & -0.0024 \\
\hline \multirow{2}{*}{ AEZ-Tropic Cool Subhumid } & $0.0037 * * *$ & & & & $0.0042 * *$ \\
\hline & -0.001 & ---- & ---- & ---- & -0.0017 \\
\hline \multirow{2}{*}{ AEZ-Tropic Warm Humid } & $0.0014 * * *$ & $0.0014 *$ & 0.0007 & $-0.0031 *$ & $0.0020 *$ \\
\hline & -0.0005 & -0.0007 & -0.0016 & -0.0018 & -0.0011 \\
\hline \multirow{2}{*}{ AEZ-Tropic Warm Subhumid } & -0.0012 & \multirow{2}{*}{----} & 0.0756 & \multirow{2}{*}{---} & 0.0013 \\
\hline & -0.0013 & & -0.0746 & & -0.0018 \\
\hline \multirow{2}{*}{ Constant } & -0.6065 & -1.1449 & -0.7334 & 0.831 & $-4.3048 * *$ \\
\hline & -0.982 & -2.7509 & -1.2242 & -2.186 & -2.0216 \\
\hline$R^{2}$ & .5161 & .7649 & .6595 & .3624 & .6487 \\
\hline $\operatorname{Adj} R^{2}$ & .51 & .7537 & .6433 & .3323 & .6314 \\
\hline$N$ & 1865 & 440 & 487 & 467 & 471 \\
\hline
\end{tabular}

Standard errors in parentheses. Significance levels: 90 percent*, 95 percent**, 99 percent***.

\section{Table B.2: Results of GLS Estimation of Number of Large Ruminants, Livestock Owners Only}

\begin{tabular}{|c|c|c|c|c|c|}
\hline & National & Central & Eastern & Northern & Western \\
\hline & $3.7841 * * *$ & $2.8035^{*}$ & $1.0420 * *$ & 1.0451 & $5.7339 * * *$ \\
\hline Housenola nirea agricumurat iabor & -0.4501 & -1.4353 & -0.4907 & -1.1217 & -0.7412 \\
\hline \multirow{2}{*}{ Agricultural Land (Hectares) } & $0.2439 * * *$ & $-0.6199 * *$ & $0.5223 * * *$ & $0.2136^{*}$ & 0.0122 \\
\hline & -0.0702 & -0.3066 & -0.0578 & -0.1237 & -0.1703 \\
\hline \multirow{2}{*}{ Pasture Land (Hectares) } & $0.2434 * * *$ & ---- & -0.3227 & 1.0345 & $0.1197 * * *$ \\
\hline & -0.0289 & & -0.2326 & -1.304 & -0.0365 \\
\hline \multirow{2}{*}{ Other Land (Hectares) } & $-0.1419 * * *$ & -0.4516 & $0.1000^{*} *^{-}$ & 0.3136 & -0.0928 \\
\hline & -0.0383 & -1.8199 & -0.0238 & -0.4143 & -0.8039 \\
\hline \multirow{2}{*}{ Goats } & $0.1753 * * *$ & $0.9161 * * *$ & $0.2315 * * *$ & $0.3886 * * *$ & 0.0098 \\
\hline & -0.0318 & -0.1642 & -0.0477 & -0.0593 & -0.0408 \\
\hline \multirow{2}{*}{ Sheep } & $0.7518 * * *$ & --- & $0.2674 * * *$ & $0.3542 * * *$ & $0.6196 * * *$ \\
\hline & -0.0595 & & -0.1006 & -0.0936 & -0.1171 \\
\hline \multirow{2}{*}{ Pigs } & 0.1158 & $0.4582 * *$ & $0.2370 * * *$ & 0.0904 & $-0.2971 *$ \\
\hline & -0.082 & -0.2258 & -0.0824 & -0.4944 & -0.1572 \\
\hline \multirow{2}{*}{ Chickens } & $0.0451 * * *$ & 0.0343 & 0.0139 & 0.0376 & $0.0661 *$ \\
\hline & -0.0161 & -0.0658 & -0.0122 & -0.0345 & -0.0387 \\
\hline \multirow{2}{*}{ Turkeys } & 0.1288 & 1.0373 & 0.0278 & 0.2182 & -0.2147 \\
\hline & -0.1743 & -0.7443 & -0.0965 & -0.7966 & -0.7459 \\
\hline
\end{tabular}


Table B.2 (Continued): Results of GLS Estimation of Number of Large Ruminants, Livestock Owners

\begin{tabular}{|c|c|c|c|c|c|}
\hline & National & Central & Eastern & Northern & Western \\
\hline \multirow{2}{*}{ Ducks } & -0.0554 & -0.0143 & -0.0176 & -0.0745 & -0.0335 \\
\hline & -0.082 & -0.2415 & -0.1004 & -0.1393 & -0.3437 \\
\hline \multirow[t]{2}{*}{ Other Birds } & -0.021 & -0.9344 & -0.0709 & 0.0905 & --- \\
\hline & -0.0983 & -1.1561 & -0.0552 & -0.2031 & \\
\hline \multirow{2}{*}{ Rabbits } & -0.1093 & -0.3638 & -0.2268 & -0.1407 & -0.0204 \\
\hline & -0.1685 & -0.433 & -0.2473 & -0.4792 & -0.2296 \\
\hline \multirow{2}{*}{ Bees } & 0.0447 & & 0.1744 & -0.0061 & -0.0598 \\
\hline & -0.0664 & ---- & -0.1869 & -0.1115 & -0.0765 \\
\hline \multirow{2}{*}{ Average Weekly Egg Production } & $-0.0034 * *$ & -0.0033 & -0.1221 & 0.0665 & 0.04 \\
\hline & -0.0016 & -0.0055 & -0.0909 & -0.1857 & -0.0421 \\
\hline \multirow{2}{*}{ Average Weekly Milk Production } & $0.0692 * * *$ & $0.2225 * * *$ & $0.0994 * * *$ & $0.1386 * * *$ & $0.0997 * * *$ \\
\hline & -0.007 & -0.0251 & -0.008 & -0.0308 & -0.0098 \\
\hline \multirow{2}{*}{ Age of Head } & 0.0107 & 0.0055 & 0.011 & 0.0234 & $0.0236 *$ \\
\hline & -0.008 & -0.0269 & -0.0081 & -0.0163 & -0.0139 \\
\hline \multirow{2}{*}{ Head is Female } & $-0.5239 *$ & -1.5187 & -0.3119 & -0.7664 & 0.0746 \\
\hline & -0.2698 & -0.9295 & -0.2498 & -0.5128 & -0.4851 \\
\hline \multirow{2}{*}{ NDVI Mean } & -0.0001 & 0.001 & 0 & -0.0004 & 0.0005 \\
\hline & -0.0002 & -0.0009 & -0.0002 & -0.0005 & -0.0004 \\
\hline \multirow{2}{*}{ NDVI Standard Deviation } & -0.0001 & -0.0002 & $0.0006 *$ & -0.0009 & -0.0004 \\
\hline & -0.0004 & -0.0019 & -0.0004 & -0.0016 & -0.0008 \\
\hline \multirow{2}{*}{ AEZ-Tropic Cool Humid } & $0.0125 * * *$ & $0.0156^{* * *}$ & $0.0091 *$ & -0.009 & $0.0093 * * *$ \\
\hline & -0.0015 & -0.0033 & -0.0053 & -0.0071 & -0.0031 \\
\hline \multirow{2}{*}{ AEZ-Tropic Cool Subhumid } & $0.0059 * * *$ & \multirow{2}{*}{---- } & \multirow{2}{*}{---- } & \multirow{2}{*}{---} & $0.0048 * *$ \\
\hline & -0.0013 & & & & -0.0021 \\
\hline \multirow{2}{*}{ AEZ-Tropic Warm Humid } & $0.0025 * * *$ & 0.0033 & 0.0006 & -0.0032 & $0.0028 *$ \\
\hline & -0.0008 & -0.0021 & -0.0018 & -0.0022 & -0.0016 \\
\hline \multirow{2}{*}{ AEZ-Tropic Warm Subhumid } & -0.0009 & \multirow{2}{*}{----} & 0.0779 & \multirow{2}{*}{0.0054} & 0.0019 \\
\hline & -0.0016 & & -0.0859 & & -0.0023 \\
\hline \multirow{2}{*}{ Constant } & -0.4283 & -8.5973 & -0.7333 & 2.1704 & $-5.2238 *$ \\
\hline & -1.2648 & -6.5031 & -1.4039 & -3.0506 & -2.783 \\
\hline$R^{2}$ & .5099 & .4805 & .6505 & .3407 & .6488 \\
\hline Adj $R^{2}$ & .502 & .4471 & .6311 & .2999 & .6258 \\
\hline$N$ & 1454 & 299 & 418 & 378 & 359 \\
\hline
\end{tabular}

Standard errors in parentheses. Significance levels: 90 percent*, 95 percent**, 99 percent***. 


\section{APPENDIX C}

Table C.1: Results of GLS Estimation of Log of Per Capita Livestock Income (PPP), All Rural Households

\begin{tabular}{|c|c|c|c|c|c|}
\hline & National & Central & Eastern & Northern & Western \\
\hline \multirow{2}{*}{ Household hired agricultural labor } & -0.1088 & -0.0706 & -0.6492 & 0.3667 & -0.0515 \\
\hline & -0.1972 & -0.4235 & -0.4179 & -0.4834 & -0.3881 \\
\hline \multirow{2}{*}{ Agricultural Land (Hectares) } & $0.0555^{*}$ & 0.1172 & 0.0295 & 0.0474 & 0.1059 \\
\hline & -0.0284 & -0.0729 & -0.0564 & -0.0499 & -0.0769 \\
\hline \multirow{2}{*}{ Pasture Land (Hectares) } & -0.0121 & 0.0569 & -0.1628 & $-1.1341 * *$ & 0.005 \\
\hline & -0.0186 & -0.0562 & -0.226 & -0.5475 & -0.0348 \\
\hline \multirow{2}{*}{ Other Land (Hectares) } & 0.0129 & 0.2811 & -0.007 & -0.0828 & -0.4334 \\
\hline & -0.0165 & -0.3777 & -0.0236 & -0.174 & -0.3883 \\
\hline \multirow{2}{*}{ Indigenous Bulls } & -0.0183 & -0.0644 & -0.0078 & -0.0109 & -0.2647 \\
\hline & -0.0356 & -0.0894 & -0.1004 & -0.0926 & -0.2089 \\
\hline \multirow{2}{*}{ Indigenous Cows } & $0.0554 * *$ & -0.0161 & 0.1391 & $0.1394 * *$ & 0.0648 \\
\hline & -0.0257 & -0.0615 & -0.1074 & -0.0674 & -0.0604 \\
\hline \multirow{2}{*}{ Indigenous Calves } & 0.06 & 0.0214 & 0.1507 & -0.0608 & $0.2834 * *$ \\
\hline & -0.0463 & -0.1364 & -0.146 & -0.0763 & -0.1113 \\
\hline \multirow{2}{*}{ Exotic Bulls } & 0.1908 & 0.1918 & 0.0792 & -1.1067 & 0.1994 \\
\hline & -0.1236 & -0.5365 & -0.3296 & -1.0207 & -0.1589 \\
\hline \multirow{2}{*}{ Exotic Cows } & $0.1544 * *$ & $0.4357 * * *$ & $0.2815^{*}$ & & -0.1817 \\
\hline & -0.0635 & -0.1577 & -0.1622 & & -0.1464 \\
\hline \multirow{2}{*}{ Exotic Calves } & $-0.1221 *$ & -0.2752 & -0.1735 & 0.4448 & 0.2675 \\
\hline & -0.072 & -0.2022 & -0.1226 & -1.7168 & -0.221 \\
\hline \multirow{2}{*}{ Donkeys } & $0.5096^{*}$ & \multirow{2}{*}{----} & $0.9828 *$ & 0.3012 & \\
\hline & -0.2665 & & -0.5771 & -0.3033 & \\
\hline \multirow{2}{*}{ Goats } & $0.1183 * * *$ & $0.1996 * * *$ & $0.1223 * * *$ & $0.0997 * * *$ & $0.1084 * * *$ \\
\hline & -0.0131 & -0.0483 & -0.0394 & -0.0248 & -0.02 \\
\hline \multirow{2}{*}{ Sheep } & $-0.0452 *$ & -0.0654 & $0.1492 *$ & -0.0119 & -0.0662 \\
\hline & -0.0269 & -0.0642 & -0.0864 & -0.0458 & -0.0597 \\
\hline \multirow{2}{*}{ Pigs } & $0.1729 * * *$ & $0.2356^{* * *}$ & 0.0937 & -0.0532 & $0.1741^{* *}$ \\
\hline & -0.034 & -0.058 & -0.0682 & -0.2113 & -0.0757 \\
\hline \multirow{2}{*}{ Chickens } & $0.0983 * * *$ & $0.0918 * * *$ & $0.0823 * * *$ & $0.0881 * * *$ & $0.1366 * * *$ \\
\hline & -0.0066 & -0.017 & -0.0099 & -0.0143 & -0.0186 \\
\hline \multirow{2}{*}{ Turkeys } & 0.1108 & 0.2329 & -0.0019 & 0.3748 & 0.2824 \\
\hline & -0.0735 & -0.2156 & -0.0797 & -0.3311 & -0.3638 \\
\hline \multirow{2}{*}{ Ducks } & $0.0743 * *$ & $0.0853 *$ & 0.1295 & 0.0442 & $0.2736^{*}$ \\
\hline & -0.0316 & -0.046 & -0.0828 & -0.07 & -0.1629 \\
\hline \multirow{2}{*}{ Other Birds } & -0.0513 & 0.495 & -0.0361 & -0.0061 & \\
\hline & -0.0417 & -0.417 & -0.0455 & -0.086 & \\
\hline
\end{tabular}

C Southern Regional Science Association 2016. 
Table C.1 (Continued): Results of GLS Estimation of Log of Per Capita Livestock Income (PPP), All Rural Households

\begin{tabular}{|c|c|c|c|c|c|}
\hline & National & Central & Eastern & Northern & Western \\
\hline \multirow{2}{*}{ Rabbits } & -0.0222 & -0.1029 & -0.1464 & 0.0666 & 0.0511 \\
\hline & -0.0711 & -0.1379 & -0.2049 & -0.2013 & -0.1112 \\
\hline \multirow{2}{*}{ Bees } & -0.0312 & & 0.1011 & $-0.1089 * *$ & 0.0207 \\
\hline & -0.0283 & ---- & -0.1551 & -0.0485 & -0.0373 \\
\hline \multirow{2}{*}{ Average Weekly Egg Production } & $-0.0064 * * *$ & $-0.0059 * * *$ & $0.0598 * *$ & -0.1136 & -0.0052 \\
\hline & -0.0007 & -0.0013 & -0.0289 & -0.0783 & -0.0208 \\
\hline \multirow{2}{*}{ Average Weekly Milk Production } & -0.0004 & -0.0093 & -0.0025 & -0.0042 & 0.0079 \\
\hline & -0.0038 & -0.0086 & -0.0108 & -0.0134 & -0.007 \\
\hline \multirow{2}{*}{ Age of Head } & -0.001 & -0.0001 & -0.0091 & $-0.0115^{* *}$ & 0.0027 \\
\hline & -0.0029 & -0.0062 & -0.0058 & -0.0058 & -0.006 \\
\hline \multirow{2}{*}{ Head is Female } & -0.1235 & $-0.3489 *$ & -0.1805 & 0.0054 & 0.0016 \\
\hline & -0.0985 & -0.2076 & -0.1896 & -0.1905 & -0.2029 \\
\hline \multirow{2}{*}{ NDVI Mean } & 0 & -0.0001 & 0.0001 & 0.0001 & 0.0001 \\
\hline & -0.0001 & -0.0002 & -0.0002 & -0.0001 & -0.0002 \\
\hline \multirow{2}{*}{ NDVI Standard Deviation } & 0 & 0.0001 & 0.0001 & -0.0001 & -0.0004 \\
\hline & -0.0001 & -0.0004 & -0.0003 & -0.0006 & -0.0003 \\
\hline \multirow{2}{*}{ AEZ-Tropic Cool Humid } & -0.0003 & $0.0015 *$ & 0.0028 & -0.0028 & $-0.0036^{* * *}$ \\
\hline & -0.0005 & -0.0008 & -0.0041 & -0.0021 & -0.0014 \\
\hline \multirow{2}{*}{ AEZ-Tropic Cool Subhumid } & -0.0006 & & & & -0.0005 \\
\hline & -0.0005 & ---- & --- & ---- & -0.001 \\
\hline \multirow{2}{*}{ AEZ-Tropic Warm Humid } & -0.0001 & 0.0006 & -0.0009 & & -0.0006 \\
\hline & -0.0003 & -0.0004 & -0.0014 & & -0.0006 \\
\hline \multirow{2}{*}{ AEZ-Tropic Warm Subhumid } & -0.0001 & & $-0.1393 * *$ & & 0.0009 \\
\hline & -0.0006 & --- & -0.0668 & --- & -0.001 \\
\hline \multirow{2}{*}{ Constant } & $1.3307 * * *$ & 1.6296 & 1.6896 & 0.9782 & 0.6858 \\
\hline & -0.4696 & -1.4027 & -1.1151 & -0.8642 & -1.1322 \\
\hline$R^{2}$ & .2587 & .2555 & .3308 & .2361 & .3436 \\
\hline $\operatorname{Adj} R^{2}$ & .2465 & .2087 & .2884 & .1909 & .302 \\
\hline $\mathrm{N}$ & 1865 & 440 & 487 & 467 & 471 \\
\hline
\end{tabular}

Standard errors in parentheses. Significance levels: 90 percent*, 95 percent**, 99 percent****. 


\section{Table C.2: Results of GLS Estimation for Log of Per Capita Livestock Income (PPP), Livestock Owners only}

\begin{tabular}{|c|c|c|c|c|c|}
\hline & National & Central & Eastern & Northern & Western \\
\hline \multirow{2}{*}{ Household hired agricultural labor } & -0.2316 & -0.236 & -0.6735 & 0.1883 & -0.2362 \\
\hline & -0.2042 & -0.444 & -0.418 & -0.5087 & -0.4313 \\
\hline \multirow{2}{*}{ Agricultural Land (Hectares) } & 0.0221 & 0.0908 & 0.0272 & 0.0265 & 0.0831 \\
\hline & -0.0317 & -0.0908 & -0.0582 & -0.0551 & -0.0907 \\
\hline \multirow{2}{*}{ Pasture Land (Hectares) } & -0.0023 & 0.0365 & -0.1271 & $-1.1527 * *$ & 0.0175 \\
\hline & -0.019 & -0.0607 & -0.226 & -0.5758 & -0.0374 \\
\hline \multirow{2}{*}{ Other Land (Hectares) } & 0.0159 & 0.5349 & -0.0097 & -0.0607 & -0.6568 \\
\hline & -0.0171 & -0.537 & -0.0236 & -0.181 & -0.4276 \\
\hline \multirow{2}{*}{ Indigenous Bulls } & -0.0162 & -0.0911 & 0.003 & ---- & -0.2471 \\
\hline & -0.037 & -0.1107 & -0.1009 & & -0.2265 \\
\hline \multirow{2}{*}{ Indigenous Cows } & 0.0299 & 0.0013 & 0.1074 & ---- & 0.0241 \\
\hline & -0.0263 & -0.0674 & -0.1079 & & -0.0652 \\
\hline \multirow{2}{*}{ Indigenous Calves } & 0.0644 & -0.0239 & 0.11833 & 0.0818 & $0.2792 * *$ \\
\hline & -0.0475 & -0.1412 & -0.1462 & -0.061 & -0.1209 \\
\hline \multirow{2}{*}{ Exotic Bulls } & 0.1623 & 0.3548 & 0.1777 & -0.6478 & 0.163 \\
\hline & -0.1279 & -0.5516 & -0.3299 & -1.0752 & -0.1707 \\
\hline \multirow{2}{*}{ Exotic Cows } & $0.1108 *$ & $0.3020 *$ & 0.2 & & -0.1677 \\
\hline & -0.0633 & -0.1638 & -0.1625 & & -0.159 \\
\hline \multirow{2}{*}{ Exotic Calves } & -0.0575 & -0.2429 & -0.1448 & 0.0095 & 0.2801 \\
\hline & -0.0738 & -0.2117 & -0.1236 & -1.8096 & -0.2409 \\
\hline \multirow{2}{*}{ Donkeys } & 0.4534 & & 0.8681 & 0.4446 & \\
\hline & -0.2769 & --- & -0.581 & -0.3209 & \\
\hline \multirow{2}{*}{ Goats } & $0.0812 * * *$ & $0.1539 * * *$ & $0.0690 *$ & ---- & $0.0841 * * *$ \\
\hline & -0.0139 & -0.0523 & -0.0406 & & -0.022 \\
\hline \multirow{2}{*}{ Sheep } & $-0.0525^{*}$ & -0.044 & 0.1411 & -0.0472 & -0.0824 \\
\hline & -0.0278 & -0.0667 & -0.0864 & -0.0481 & -0.0643 \\
\hline \multirow{2}{*}{ Pigs } & $0.0986 * * *$ & $0.1764 * *$ & 0.05 & -0.0928 & 0.0842 \\
\hline & -0.036 & -0.069 & -0.0684 & -0.2209 & -0.0834 \\
\hline \multirow{2}{*}{ Chickens } & $0.0731 * * *$ & $0.0587 * * *$ & $0.064 * * *$ & $0.0751 * * *$ & $0.0970 * * *$ \\
\hline & -0.0071 & -0.0195 & -0.0103 & -0.015 & -0.0206 \\
\hline \multirow{2}{*}{ Turkeys } & 0.0804 & 0.2276 & -0.0264 & 0.2836 & 0.2968 \\
\hline & -0.076 & -0.2178 & -0.08 & -0.3472 & -0.3964 \\
\hline \multirow{2}{*}{ Ducks } & 0.0502 & 0.0938 & 0.0981 & 0.0172 & 0.1466 \\
\hline & -0.0358 & -0.0695 & -0.0831 & -0.0743 & -0.1811 \\
\hline \multirow{2}{*}{ Other Birds } & -0.0521 & 0.7892 & -0.0276 & -0.0233 & \\
\hline & -0.0432 & -0.6672 & -0.0456 & -0.09 & \\
\hline \multirow{2}{*}{ Rabbits } & -0.0447 & -0.1014 & -0.163 & 0.0709 & -0.0144 \\
\hline & -0.0734 & -0.1252 & -0.205 & -0.2123 & -0.1214 \\
\hline
\end{tabular}

C Southern Regional Science Association 2016. 
Table C.2 (Continued): Results of GLS Estimation for Log of Per Capita Livestock Income (PPP), Livestock Owners only

\begin{tabular}{|c|c|c|c|c|c|}
\hline & National & Central & Eastern & Northern & Western \\
\hline \multirow{4}{*}{ Average Weekly Egg Production } & -0.0227 & \multirow{2}{*}{----} & 0.0864 & -0.0567 & 0.0237 \\
\hline & -0.0292 & & -0.1556 & -0.0497 & -0.0407 \\
\hline & $-0.0048 * * *$ & $-0.0037 * *$ & $0.1452 *$ & -0.0959 & -0.0053 \\
\hline & -0.0007 & -0.0017 & -0.0754 & -0.0824 & -0.0226 \\
\hline \multirow{2}{*}{ Average Weekly Milk Production } & 0.0002 & -0.0091 & 0.0013 & -0.0046 & 0.0066 \\
\hline & -0.0039 & -0.0095 & -0.0109 & -0.0141 & -0.0075 \\
\hline \multirow{2}{*}{ Age of Head } & -0.0013 & -0.0062 & 0.0003 & -0.01 & -0.0001 \\
\hline & -0.0035 & -0.0078 & -0.0067 & -0.0072 & -0.0074 \\
\hline \multirow{2}{*}{ Head is Female } & -0.0763 & -0.4415 & -0.1166 & 0.0609 & 0.0559 \\
\hline & -0.1182 & -0.2743 & -0.2079 & -0.2274 & -0.2564 \\
\hline \multirow{2}{*}{ NDVI Mean } & 0 & -0.0001 & 0 & -0.0003 & -0.0001 \\
\hline & -0.0001 & -0.0003 & -0.0002 & -0.0002 & -0.0002 \\
\hline \multirow{2}{*}{ NDVI Standard Deviation } & 0 & -0.0001 & 0 & -0.0001 & -0.0003 \\
\hline & -0.0002 & -0.0005 & -0.0003 & -0.0006 & -0.0003 \\
\hline \multirow{2}{*}{ AEZ-Tropic Cool Humid } & 0 & 0.0013 & 0.002 & \multirow{4}{*}{0.0004} & ---- \\
\hline & -0.0007 & -0.001 & -0.0045 & & \\
\hline \multirow{2}{*}{ AEZ-Tropic Cool Subhumid } & -0.0001 & & & & ---- \\
\hline & -0.0006 & --- & $-\cdots$ & & \\
\hline \multirow{2}{*}{ AEZ-Tropic Warm Humid } & 0.0001 & $0.0011 *$ & -0.0005 & \multirow{2}{*}{----} & 0 \\
\hline & -0.0003 & -0.0006 & -0.0015 & & -0.0007 \\
\hline \multirow{2}{*}{ AEZ-Tropic Warm Subhumid } & -0.0004 & \multirow{2}{*}{----} & $-0.1979 * * *$ & \multirow{2}{*}{---- } & ---- \\
\hline & -0.0007 & & -0.0717 & & \\
\hline \multirow{2}{*}{ Constant } & $2.0206 * * *$ & 2.2451 & $2.0886^{*}$ & $3.9912 * * *$ & $2.2306^{*}$ \\
\hline & -0.5546 & -1.8932 & -1.195 & -1.3766 & -1.3481 \\
\hline$R^{2}$ & .1434 & .1571 & .2502 & .1023 & .2151 \\
\hline $\operatorname{Adj} R^{2}$ & .1253 & .0765 & .1942 & .0439 & .1562 \\
\hline$N$ & 1454 & 299 & 418 & 378 & 359 \\
\hline
\end{tabular}

Standard errors in parentheses. Significance levels: 90 percent*, 95 percent**, 99 percent***. 
APPENDIX D

Table D.1: Results of GLS Estimation of Share of Income from Livestock, All Rural Households

\begin{tabular}{|c|c|c|c|c|c|}
\hline & National & Central & Eastern & Northern & Western \\
\hline \multirow{2}{*}{ Household hired agricultural labor } & $-0.0478 * *$ & 0.0092 & -0.0806 & -0.0706 & -0.0298 \\
\hline & -0.0232 & -0.0523 & -0.0562 & -0.0749 & -0.0227 \\
\hline \multirow{2}{*}{ Agricultural Land (Hectares) } & 0.0024 & 0.0063 & -0.0013 & 0.0021 & -0.0053 \\
\hline & -0.0033 & -0.0089 & -0.0076 & -0.0078 & -0.0044 \\
\hline \multirow{2}{*}{ Pasture Land (Hectares) } & -0.0016 & 0.0099 & -0.0087 & $-0.1835 * *$ & $-0.0039 *$ \\
\hline & -0.0022 & -0.007 & -0.0304 & -0.0853 & -0.002 \\
\hline \multirow{2}{*}{ Other Land (Hectares) } & -0.0008 & 0.0017 & -0.0013 & 0.0379 & -0.0306 \\
\hline & -0.0019 & -0.0466 & -0.0032 & -0.0273 & -0.0227 \\
\hline \multirow{2}{*}{ Indigenous Bulls } & -0.0032 & -0.0128 & -0.0058 & 0.0125 & -0.011 \\
\hline & -0.0042 & -0.0111 & -0.0135 & -0.0143 & -0.0121 \\
\hline \multirow{2}{*}{ Indigenous Cows } & 0.0021 & -0.0107 & 0.012 & 0.0012 & $0.0079 * *$ \\
\hline & -0.003 & -0.0075 & -0.0144 & -0.0102 & -0.0035 \\
\hline \multirow{2}{*}{ Indigenous Calves } & $0.0124 * *$ & 0.017 & 0.0204 & 0.0106 & $0.0242 * * *$ \\
\hline & -0.0054 & -0.0169 & -0.0196 & -0.0118 & -0.0065 \\
\hline \multirow{2}{*}{ Exotic Bulls } & 0.009 & 0.0317 & 0.0091 & \multirow{2}{*}{---- } & $0.0157 *$ \\
\hline & -0.0145 & -0.0658 & -0.0443 & & -0.0093 \\
\hline \multirow{2}{*}{ Exotic Cows } & -0.0019 & 0.0314 & -0.0004 & \multirow{2}{*}{----} & -0.004 \\
\hline & -0.0075 & -0.0195 & -0.0218 & & -0.0085 \\
\hline \multirow{2}{*}{ Exotic Calves } & 0.0032 & -0.0281 & 0.0162 & \multirow{2}{*}{----} & 0.0064 \\
\hline & -0.0085 & -0.0248 & $0.0165)$ & & -0.0129 \\
\hline \multirow{2}{*}{ Donkeys } & $0.0572 *$ & \multirow{2}{*}{---- } & $0.1413 *$ & 0.0668 & \\
\hline & -0.0313 & & -0.0776 & -0.0474 & \\
\hline \multirow{2}{*}{ Goats } & $0.0046^{* * *}$ & 0.0075 & 0.0035 & \multirow{2}{*}{----} & $0.0024 * *$ \\
\hline & -0.0015 & -0.006 & -0.0053 & & -0.0012 \\
\hline \multirow{2}{*}{ Sheep } & $-0.008 * *$ & -0.0039 & 0.0047 & $-0.0145^{* *}$ & $-0.0100 * * *$ \\
\hline & -0.0032 & -0.0079 & -0.0116 & -0.0071 & -0.0035 \\
\hline \multirow{2}{*}{ Pigs } & 0.0024 & 0.0051 & -0.001 & -0.0221 & $0.0092 * *$ \\
\hline & -0.004 & -0.0072 & -0.0092 & -0.0328 & -0.0044 \\
\hline \multirow{2}{*}{ Chickens } & $0.0031 * * *$ & 0.0027 & 0.0018 & $0.0060 * * *$ & \multirow{2}{*}{--} \\
\hline & -0.0008 & -0.0021 & -0.0013 & -0.0022 & \\
\hline \multirow{2}{*}{ Turkeys } & -0.0025 & -0.0135 & -0.0054 & \multirow{2}{*}{----} & -0.0007 \\
\hline & -0.0086 & -0.0266 & -0.0107 & & -0.0213 \\
\hline \multirow{2}{*}{ Ducks } & $0.0066^{*}$ & 0.0052 & $0.0194 *$ & 0.005 & -0.0057 \\
\hline & -0.0037 & -0.0057 & -0.0111 & -0.0092 & -0.0095 \\
\hline \multirow{2}{*}{ Other Birds } & $-0.0092 *$ & 0.018 & 0.0003 & $-0.0285^{* *}$ & \multirow[t]{2}{*}{---- } \\
\hline & -0.0049 & -0.0516 & -0.0061 & -0.0134 & \\
\hline \multirow{2}{*}{ Rabbits } & -0.0065 & -0.0187 & 0.0018 & -0.0001 & -0.0033 \\
\hline & -0.0084 & -0.017 & -0.0275 & -0.0314 & -0.0065 \\
\hline
\end{tabular}

C Southern Regional Science Association 2016. 
Table D.1: Results of GLS Estimation of Share of Income from Livestock, All Rural Households

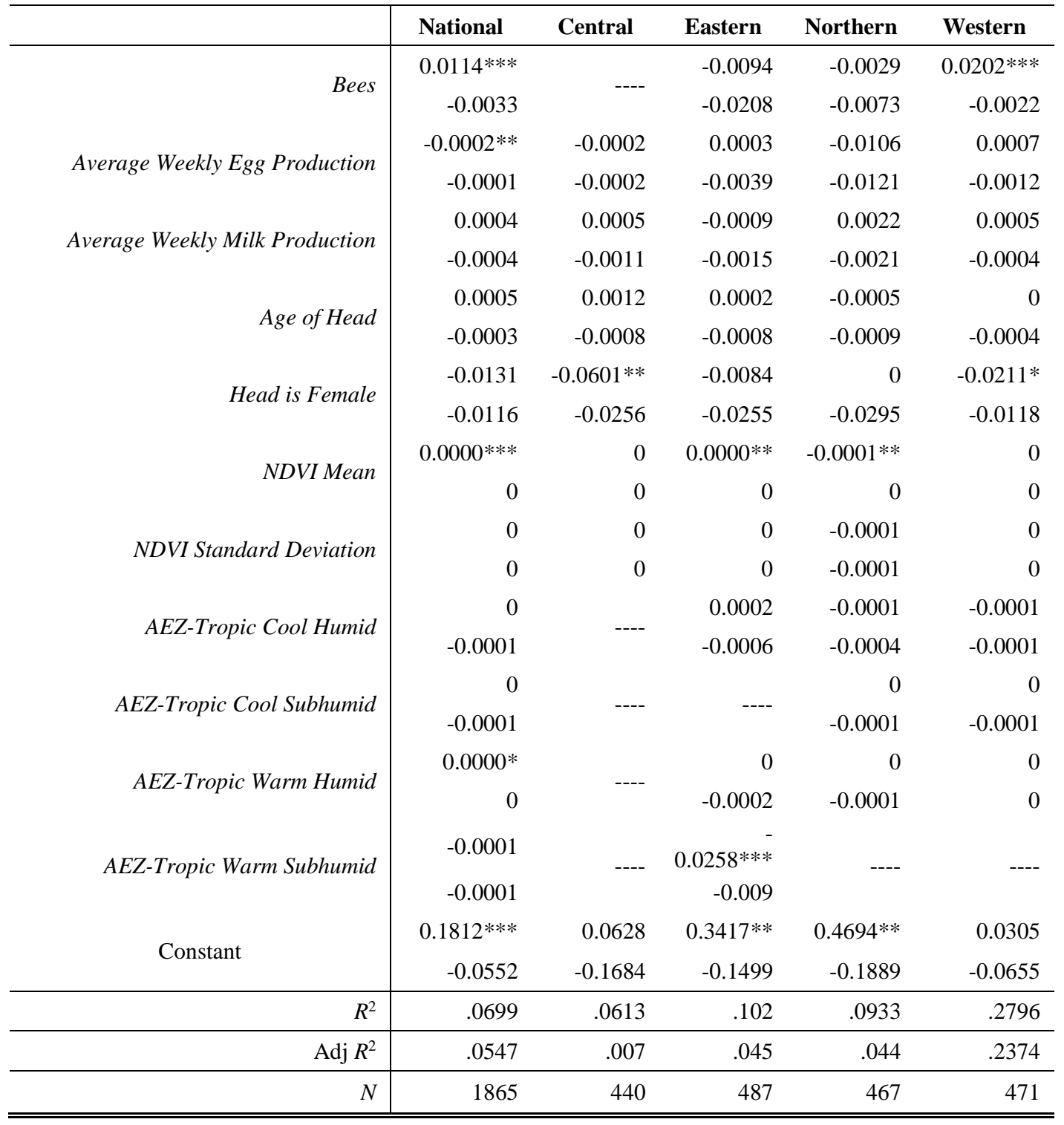

Standard errors in parentheses. Significance levels: 90 percent*, 95 percent**, 99 percent***.

(c) Southern Regional Science Association 2016. 
Table D.2: Results of GLS Estimation for Share of Income from Livestock, Livestock Owners Only

\begin{tabular}{|c|c|c|c|c|c|}
\hline & National & Central & Eastern & Northern & Western \\
\hline \multirow{2}{*}{ Household hired agricultural labor } & $-0.0503 * *$ & -0.0057 & -0.0785 & -0.0728 & -0.0273 \\
\hline & -0.0255 & -0.0587 & -0.0606 & -0.078 & -0.0268 \\
\hline \multirow{2}{*}{ Agricultural Land (Hectares) } & 0 & 0.003 & -0.0012 & -0.0028 & -0.0091 \\
\hline & -0.004 & -0.0126 & -0.0084 & -0.0086 & -0.0057 \\
\hline \multirow{2}{*}{ Pasture Land (Hectares) } & -0.0011 & ---- & -0.0092 & $-0.1732 *$ & -0.0027 \\
\hline & -0.0024 & & -0.0328 & -0.0885 & -0.0023 \\
\hline \multirow{2}{*}{ Other Land (Hectares) } & -0.001 & ---- & -0.0015 & 0.0437 & -0.0315 \\
\hline & -0.0021 & & -0.0034 & -0.0284 & -0.0267 \\
\hline \multirow{2}{*}{ Indigenous Bulls } & -0.0031 & -0.0035 & -0.0062 & 0.012 & -0.0127 \\
\hline & -0.0046 & -0.0071 & -0.0146 & -0.015 & -0.0141 \\
\hline \multirow{2}{*}{ Indigenous Cows } & 0.0012 & ---- & 0.0102 & -0.0058 & 0.0058 \\
\hline & -0.0033 & & -0.0156 & -0.011 & -0.0041 \\
\hline \multirow{2}{*}{ Indigenous Calves } & $0.0126^{* *}$ & ---- & 0.0194 & 0.0149 & $0.0255^{* * *}$ \\
\hline & -0.0059 & & -0.0212 & -0.0124 & -0.0076 \\
\hline \multirow{2}{*}{ Exotic Bulls } & 0.0076 & 0.006 & 0.014 & \multirow{2}{*}{---- } & 0.0156 \\
\hline & -0.016 & -0.073 & -0.0478 & & -0.0108 \\
\hline \multirow{2}{*}{ Exotic Cows } & -0.0026 & 0.027 & -0.0022 & \multirow{2}{*}{----} & -0.0069 \\
\hline & -0.0079 & -0.0206 & -0.0236 & & -0.0099 \\
\hline \multirow{2}{*}{ Exotic Calves } & 0.0058 & -0.0155 & 0.0163 & \multirow{2}{*}{---} & 0.0103 \\
\hline & -0.0092 & -0.0206 & -0.0179 & & -0.015 \\
\hline \multirow{2}{*}{ Donkeys } & 0.0536 & \multirow{2}{*}{---} & 0.138 & 0.0607 & \multirow{2}{*}{--} \\
\hline & -0.0346 & & -0.0842 & -0.0494 & \\
\hline \multirow{2}{*}{ Goats } & $0.0037 * *$ & $0.0128 *$ & 0.0011 & \multirow{2}{*}{0.0067} & 0.0018 \\
\hline & -0.0017 & -0.0073 & -0.0059 & & -0.0014 \\
\hline \multirow{2}{*}{ Sheep } & $-0.0086^{* *}$ & -0.0006 & 0.004 & $0.0181^{* *}$ & $-0.0108 * * *$ \\
\hline & -0.0035 & -0.008 & -0.0125 & -0.0075 & -0.004 \\
\hline \multirow{2}{*}{ Pigs } & 0.0036 & 0.0088 & -0.0025 & -0.0243 & 0.006 \\
\hline & -0.0045 & -0.0093 & -0.0099 & -0.0341 & -0.0052 \\
\hline \multirow{2}{*}{ Chickens } & $0.0027 * * *$ & 0.0025 & 0.0011 & $0.0053 * *$ & \multirow{2}{*}{$0.0023 *$} \\
\hline & -0.0009 & -0.0028 & -0.0015 & -0.0024 & \\
\hline \multirow{2}{*}{ Turkeys } & -0.0028 & -0.0133 & -0.0063 & \multirow{2}{*}{0.0108} & 0.0019 \\
\hline & -0.0095 & -0.0311 & -0.0116 & & -0.0247 \\
\hline \multirow{2}{*}{ Ducks } & 0.0073 & 0.0079 & 0.0176 & 0.0033 & -0.0064 \\
\hline & -0.0045 & -0.0096 & -0.012 & -0.0096 & -0.0113 \\
\hline \multirow{2}{*}{ Other Birds } & $-0.0093 *$ & ---- & 0.001 & $0.0278^{-} *$ & \multirow[t]{2}{*}{-} \\
\hline & -0.0054 & & -0.0066 & -0.0139 & \\
\hline Rabbits & -0.0068 & -0.0187 & 0.0008 & -0.0039 & -0.0037 \\
\hline Rabbits & -0.0092 & -0.0179 & -0.0297 & -0.0326 & -0.0075 \\
\hline
\end{tabular}

(c) Southern Regional Science Association 2016. 
Table D.2 (Continued): Results of GLS Estimation for Share of Income from Livestock, Livestock Owners Only

\begin{tabular}{|c|c|c|c|c|c|}
\hline & National & Central & Eastern & Northern & Western \\
\hline \multirow{4}{*}{ Average Weekly Egg Production } & $0.0113 * * *$ & & -0.0091 & -0.0066 & $0.0193 * * *$ \\
\hline & -0.0037 & --- & -0.0225 & -0.0078 & -0.0025 \\
\hline & $-0.0002 * *$ & -0.0002 & 0.0019 & -0.011 & 0.0004 \\
\hline & -0.0001 & -0.0002 & -0.0109 & -0.0126 & -0.0014 \\
\hline \multirow{2}{*}{ Average Weekly Milk Production } & 0.0004 & --- & -0.0008 & 0.0018 & 0.0005 \\
\hline & -0.0005 & & -0.0016 & -0.0022 & -0.0005 \\
\hline \multirow{2}{*}{ Age of Head } & 0.0007 & 0.0012 & 0.0007 & -0.0001 & -0.0002 \\
\hline & -0.0004 & -0.0011 & -0.001 & -0.0011 & -0.0005 \\
\hline \multirow{2}{*}{ Head is Female } & -0.0111 & $-0.0762 * *$ & -0.006 & 0.0081 & -0.026 \\
\hline & -0.0148 & -0.0387 & -0.0301 & -0.035 & -0.016 \\
\hline \multirow{2}{*}{ NDVI Mean } & $0.0000 * * *$ & ---- & $-0.0001 * *$ & $-0.0001 *$ & 0 \\
\hline & 0 & \multirow{5}{*}{-0.0001} & 0 & 0 & 0 \\
\hline \multirow{2}{*}{ NDVI Standard Deviation } & 0 & & 0 & -0.0001 & 0 \\
\hline & 0 & & 0 & -0.0001 & 0 \\
\hline \multirow{2}{*}{ AEZ-Tropic Cool Humid } & 0 & & 0.0002 & -0.0002 & -0.0001 \\
\hline & -0.0001 & & -0.0006 & -0.0005 & -0.0001 \\
\hline \multirow{2}{*}{ AEZ-Tropic Cool Subhumid } & 0.0001 & \multirow{2}{*}{----} & \multirow{2}{*}{---- } & 0 & 0 \\
\hline & -0.0001 & & & -0.0002 & -0.0001 \\
\hline \multirow{2}{*}{ AEZ-Tropic Warm Humid } & $0.0001 * *$ & \multirow{2}{*}{----} & 0 & -0.0001 & 0.0001 \\
\hline & 0 & & -0.0002 & -0.0002 & -0.0001 \\
\hline \multirow{2}{*}{ AEZ-Tropic Warm Subhumid } & -0.0001 & \multirow{2}{*}{----} & $-0.0306 * * *$ & - & 00001 \\
\hline & -0.0001 & & -0.0104 & -- & 0.0001 \\
\hline \multirow{2}{*}{ Constant } & $0.2169 * * *$ & -0.0107 & $0.3983 * *$ & $0.4977 * *$ & 0.0521 \\
\hline & -0.0694 & -0.0618 & $(0.1732$ & -0.2314 & -0.0923 \\
\hline$R^{2}$ & .0644 & .0487 & .0998 & .1168 & .2857 \\
\hline $\operatorname{Adj} R^{2}$ & .0446 & -.0088 & .0325 & .0514 & .2251 \\
\hline$N$ & 1454 & 299 & 418 & 378 & 359 \\
\hline
\end{tabular}

Standard errors in parentheses. Significance levels: 90 percent*, 95 percent**, 99 percent***. 


\section{APPENDIX E}

\section{Maps of Livestock Income using OLS and Tobit}
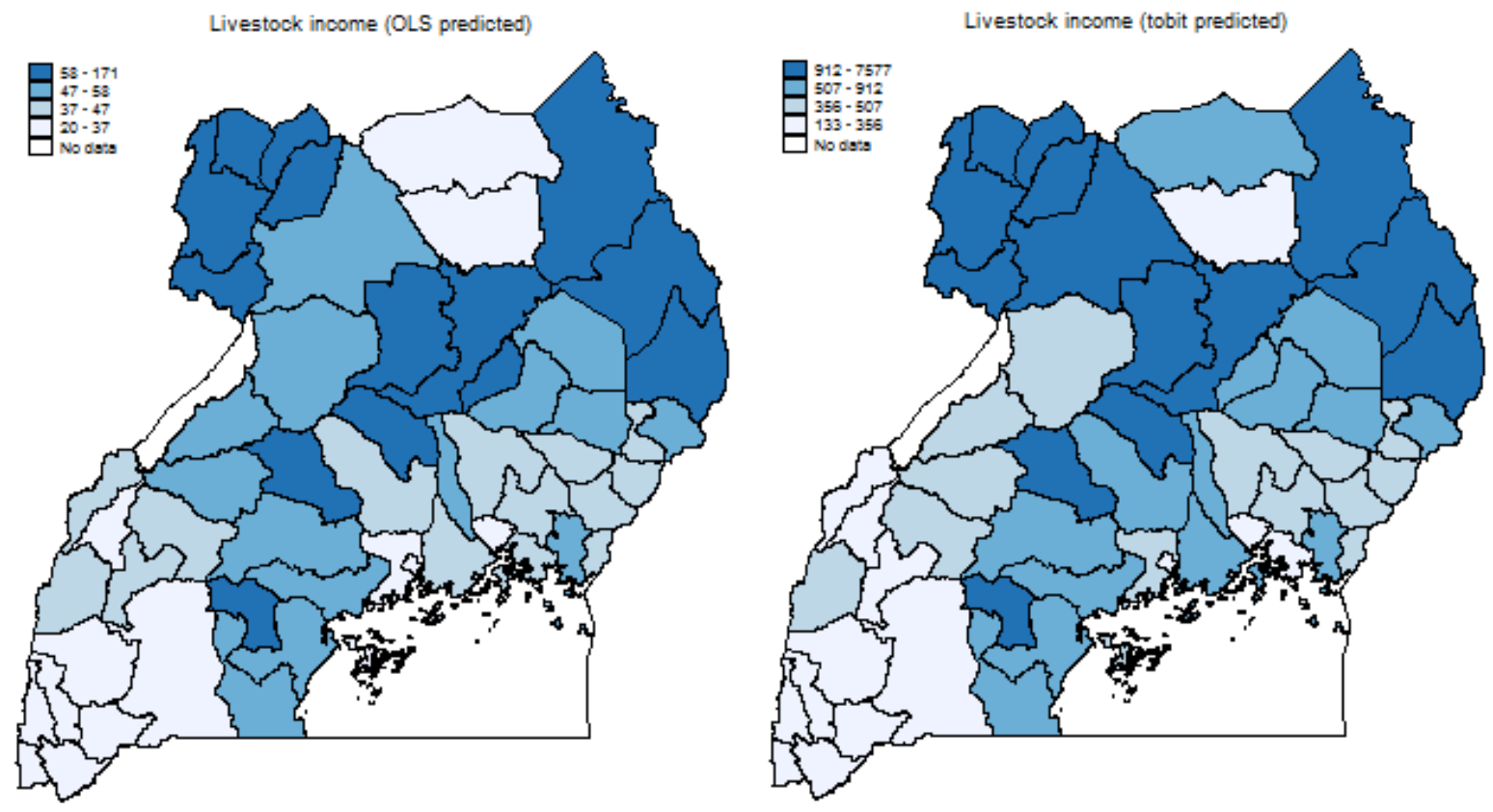

\section{APPENDIX F}

\section{Maps of Livestock Income Share using OLS and Tobit}
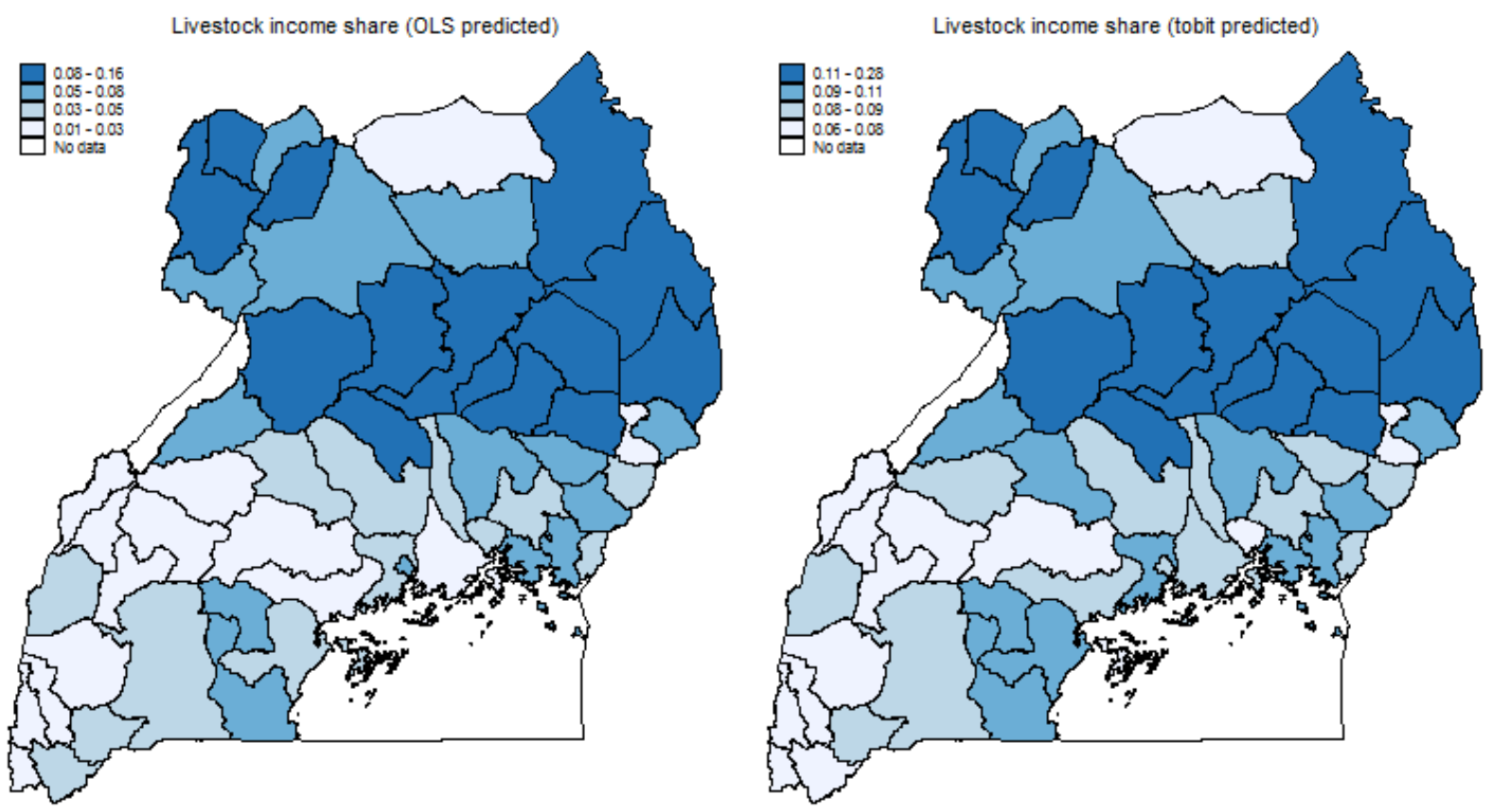

(c) Southern Regional Science Association 2016. 
APPENDIX G

Maps at the Subcounty Level
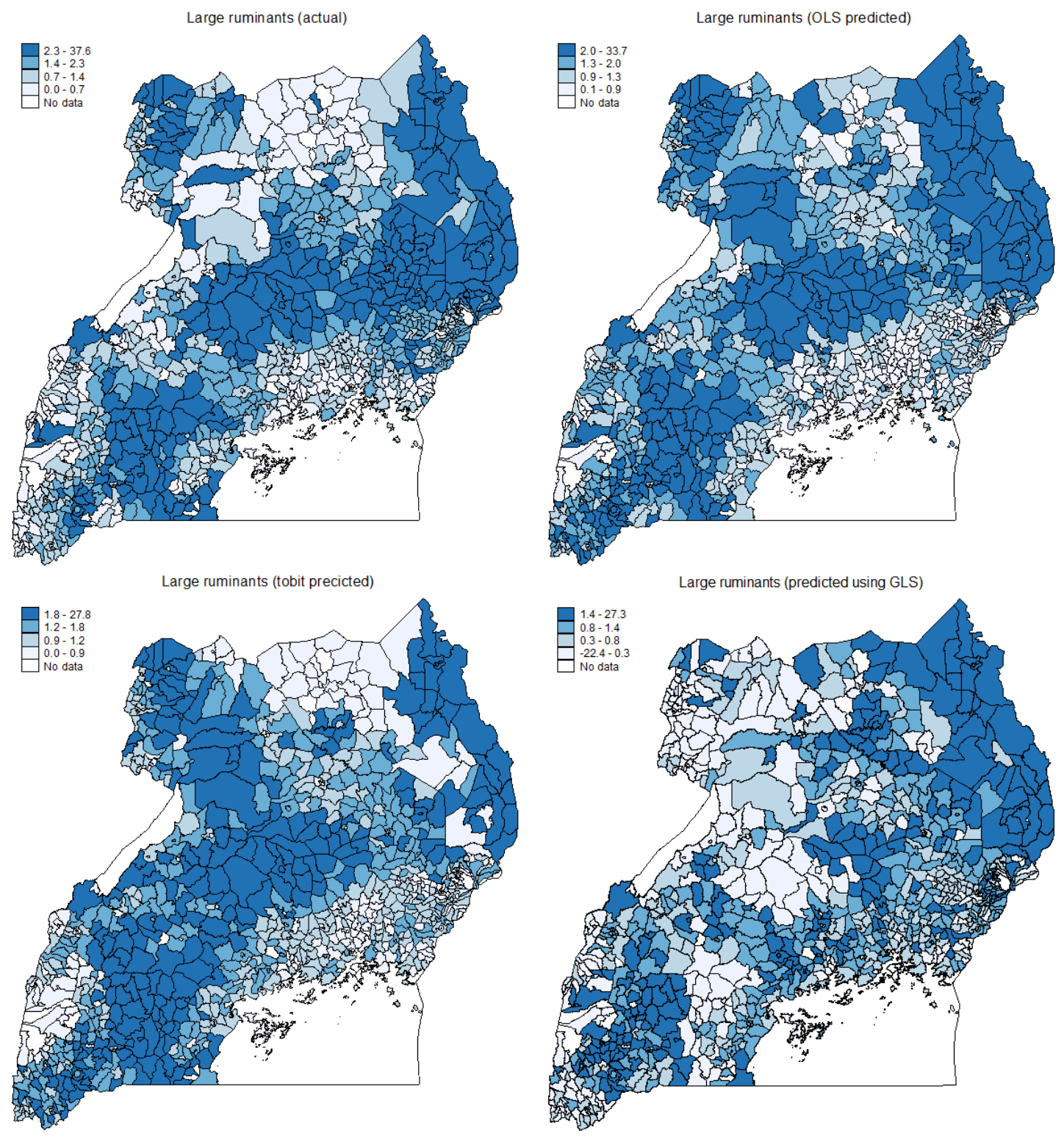

(c) Southern Regional Science Association 2016. 

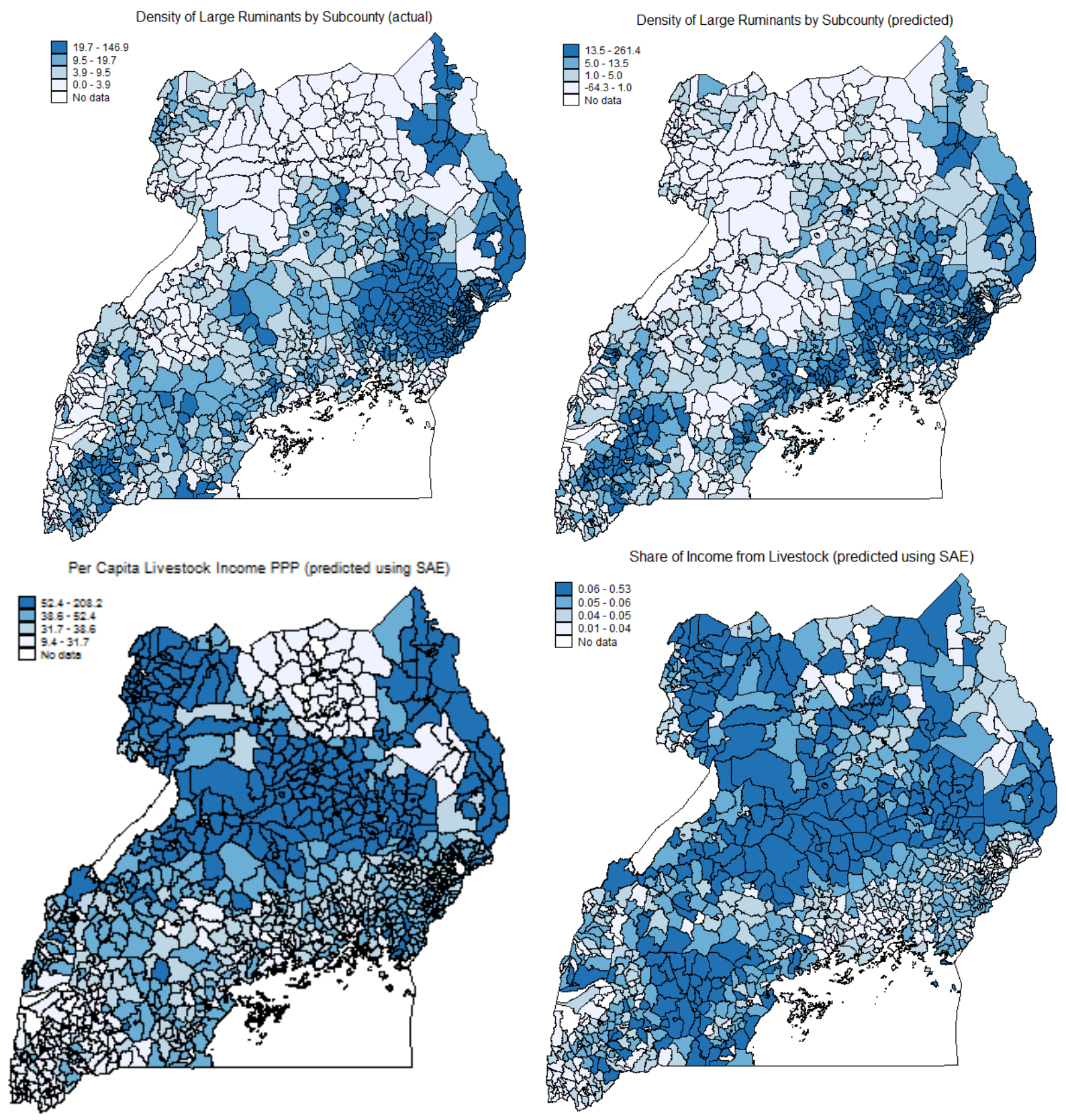

(c) Southern Regional Science Association 2016. 

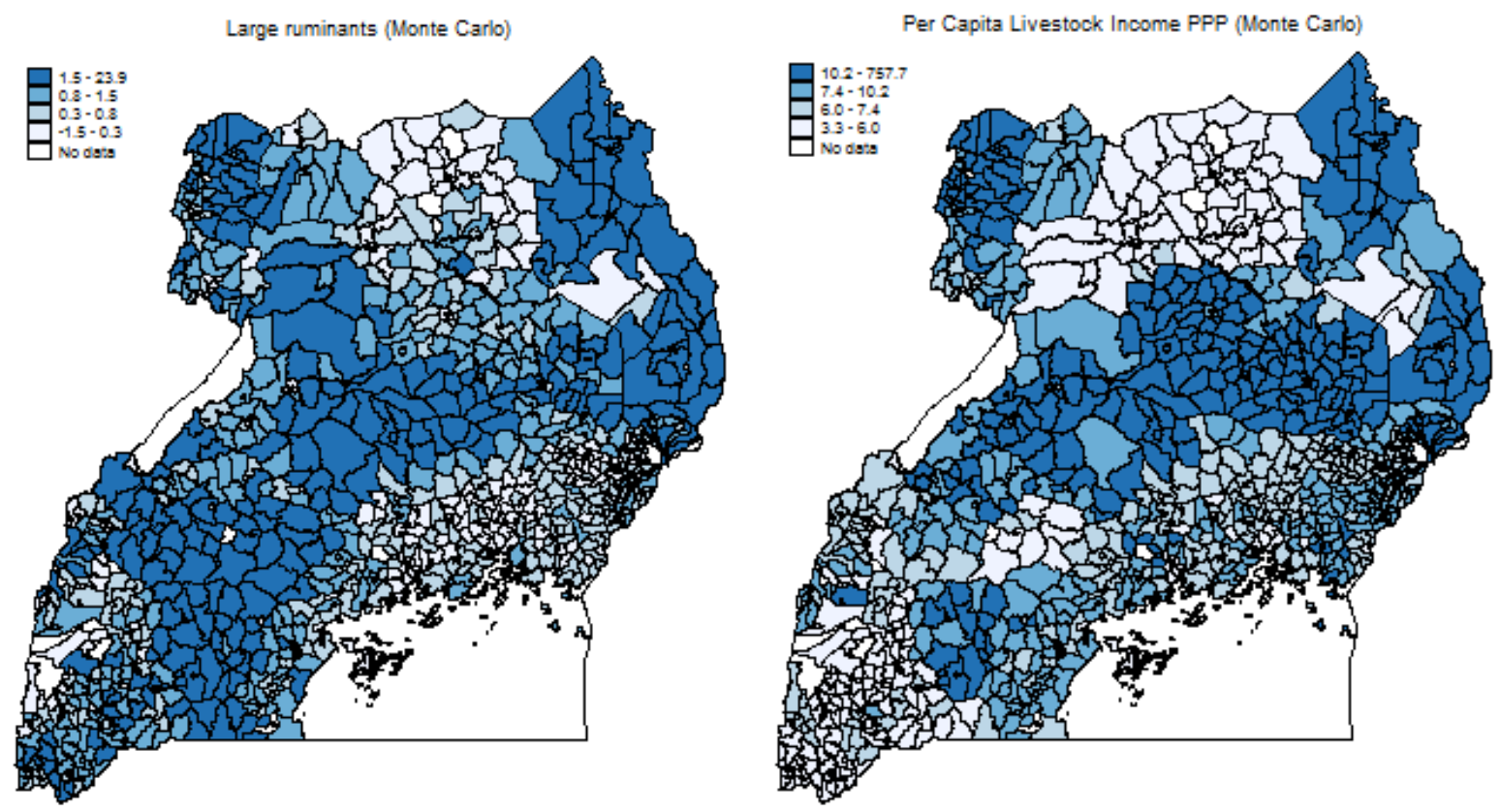

(c) Southern Regional Science Association 2016. 